\title{
VERTEBRATE RESPONSES TO SPATIOTEMPORAL VARIATION IN SEED PRODUCTION OF MAST-FRUITING DIPTEROCARPACEAE
}

\author{
L. M. CurRan ${ }^{1,3}$ AND M. LeIGHTON ${ }^{2}$ \\ ${ }^{1}$ Department of Biology and School of Natural Resources and Environment, University of Michigan, \\ Ann Arbor, Michigan 48109-1048 USA \\ ${ }^{2}$ Department of Anthropology, Harvard University, Cambridge, Massachusetts 02138-2094 USA
}

\begin{abstract}
To examine the interspecific reproductive synchrony of Dipterocarpaceae with vertebrate responses to seed availablity, we monitored the spatiotemporal distribution and phenology of more than 2367 adult dipterocarp individuals of 54 species from March 1985 to January 1993 in the Gunung Palung National Park, West Kalimantan, Indonesia. Seven vegetational formations were sampled along an altitudinal gradient from peat swamp forest ( $5 \mathrm{~m}$ a.s.1. [above sea level]) across lowlands to upper montane zones (1100 m a.s.1.) that encompassed two upland valley complexes in a $15-\mathrm{km}^{2}$ area. Four significant reproductive events were documented: (1) a common lowland species reproduced outside of mast events in 1986 and in 1990; (2) a localized lowland "minor" mast event in 1986 in which $24.3 \%$ of the adult trees (21 spp.) participated; (3) a major community-wide mast event (92.8\%, 48 spp.) in 1987, just 6 mo after the minor event; and (4) another major community-wide mast fruiting event after a 4-yr intermast interval (88\%, 48 spp.) in 1991. West Kalimantan export records of illipe nut (Dipterocarpaceae: Shorea section Pachycarpae) from 1968 to 1997 were compiled as a baseline measure of the frequency and relative intensity of dipterocarp mast-fruiting events in the region $(\mathrm{CV}$ $=152 \%$ ). A "bumper crop" occurred about every $5 \pm 2.6 \mathrm{yr}$ (mean \pm 1 sD; range 3-9 yr). Fruit production was significantly associated with El Niño-Southern Oscillation (ENSO) events. The 1987 and 1991 mast events monitored were the third and fourth largest export years in the province since 1968.
\end{abstract}

Because of the disputed role of vertebrate seed predators in causing and maintaining mast-fruiting behavior, the response of seed-eating vertebrates to this spatiotemporal variation in dipterocarp seed production was examined. Seed of a common, but asynchronous, lowland species was largely consumed by vertebrates. In the 1986 minor mast, 21 dipterocarp species that produced 60000 seeds/ha (dry mass $46 \mathrm{~kg} / \mathrm{ha}$ ) lost all monitored viable seed to a diversity of resident and nomadic vertebrate seed predators. Timed with dipterocarp seed production in all mast events, nomadic vertebrates increased their populations through both reproduction and regional movement (numerical response). However, in both the 1987 and 1991 mast events, resident vertebrates destroyed only $1.5 \%$ and $2.6 \%$ of community seed production, and predation was recorded only in the tails of the fruit-fall distribution. During these community mast events, resident vertebrates switched from dipterocarp seed to feed on fruit and seed from other available species. Nomadic vertebrates arrived late in the fruit-fall period during both major mast events and, thus, were able to destroy only seed dispersed in the final 1-3 wk of fruit-fall. Seed escape, and thus regeneration, only occurred in major mast events when all dipterocarp species across large areas participated. Considerable seedling recruitment was recorded in both the 1987 ( 995000 seedlings/ha) and 1991 (155824 \pm 36764 seedlings/ha) mast events.

Results from this natural experiment indicate that resident and nomadic vertebrates cause stabilizing selection for tight interspecific synchrony of dipterocarp seedfall over vast regions. Although the pattern generally conformed to the predator-satiation hypothesis, the observed mechanisms for seed escape within a mast-fruiting event did not. Resident and nomadic vertebrate foraging and ranging patterns resulted in dipterocarp seed "escape" rather than local "swamping" with copious seed production per se. To account for these observations, two hypotheses, "interfamilial satiation" and "regional escape," were developed. The period of seed availability and length of the regional intermast interval is examined with seed-predator reproduction and behavior to assess the impact of seed availability on seed-predator populations. The importance of rare events and appropriate spatial scale for investigating evolutionary and ecological processes such as mast fruiting are addressed.

Key words: Borneo; density dependence; Dipterocarpaceae; El Niño-Southern Oscillation; mast fruiting; phenology; predator satiation; reproductive synchrony; seed predation; seedling recruitment; Sus barbatus; tropical trees.

Manuscript received 16 March 1998; revised 18 December 1998; accepted 29 December 1998; final version received 5 February 1999.

3 E-mail: lcurran@umich.edu 


\section{INTRODUCTION}

Pre-dispersal and post-dispersal seed predators can limit plant recruitment and may cause total crop failure (Janzen 1969, 1970, 1971, 1978, De Steven 1982, 1983, Louda $1982 a, b$, among others). Seed predation can be an important ecological and evolutionary force affecting plant community diversity, demography, and phenology at individual, population, and community levels (Harper 1977, Hubbell 1980, Crawley 1983, Schupp 1987). Thus, seed predation has the selective potential to shape phenological characteristics and to favor traits such as mast fruiting that reduce seed predation.

It has been suggested that mast fruiting (episodic synchronous reproduction interspersed with periods of little or no seed production) by a population or a community of tree species is a reproductive strategy that evolved to satiate seed predators (Salisbury 1942, Janzen 1974). Janzen (1974) proposed that mast fruiting provides an overabundance of seed (predator satiation), thus ensuring that some seeds escape predation and establish. This is a classic problem in evolutionary ecology, and a major resurgence of scientific interest is underway to determine the relative importance of several compatible hypotheses, including predator satiation, proposed to explain the evolution and/or maintenance of mast fruiting in tree populations (Norton and Kelly 1988, Ims 1990, Smith et al. 1990, Lalonde and Roitberg 1992, Sork 1993, Sork et al. 1993, Waller 1993, Curran 1994, Kelly 1994, Koenig et al. 1994, Crawley and Long 1995, Koenig and Knops 1995, Tapper 1996, Curran and Webb 2000).

Seed predation has been examined in mast-fruiting trees in a number of case studies and plant population biology texts (e.g., Harper and White 1974, Harper 1977, Waller 1979, Silvertown 1982, Crawley 1983, Fenner 1985). Previous field studies are inconclusive because they (1) examined data originally collected for other reasons that gave equivocal results (e.g., Waller 1979, Silvertown 1980, Norton and Kelly 1988); (2) used indirect estimates of predation (e.g., Silvertown 1980, Jensen 1982, Schupp 1987, Norton and Kelly 1988); (3) were complicated by disperser-predators and the unknown ultimate fate of removed seeds (Sork and Boucher 1977, Sork et al. 1993); or (4) employed phytocentric studies that quantified only the impact of insects (e.g., DeSteven 1982, 1983, Toy et al. 1992, Sork et al. 1993, Tapper 1996).

The predator satiation hypothesis predicts that individuals recruit well in major mast years, but poorly, if at all, outside of seasons with large seed production. Seed predators are expected to destroy much seed, but during peak fruit fall, many seeds escape predators and then establish. The degree of reproductive synchrony determines the rate of seed predation and, thus, per capita seed survival and recruitment. Few empirical studies on seed predation in mast-fruiting populations have documented the interaction between reproductive synchrony and the rate of seed predation (Ims 1990; but see Augspurger 1981, Wright 1990). The pattern and timing of seed predation in mast-fruiting populations is the critical parameter to measure, rather than absolute or proportional seed losses of a total reproductive event (e.g., Silvertown 1980, 1982, Jensen 1982, 1985, Wolff 1996). Detailed observations on the proportional impact of seed predators with different degrees of reproductive synchrony across multiple spatial scales is essential to test the predator satiation hypothesis (Janzen 1976, Gochfeld 1982, Ims 1990). Janzen (1976) outlined a test of the predator satiation hypothesis: the fraction of seeds eaten throughout the temporal distribution of seedfall is quantified, and seed predators destroy the smallest percentage of seeds in the central portion of the seedfall distribution and the largest percentage in the tails of this distribution.

Testing the predator satiation hypothesis presents a significant challenge because it requires assessing both prey (seeds) availability and predator (seed-eating vertebrates and insects) behavior, as well as their dynamic interactions. A rigorous investigation of the predator satiation hypothesis must include the functional and/ or numerical response of the frugivores and granivores, as well as the large and multiple-scale spatiotemporal distribution of fruiting trees and populations.

\section{Bornean dipterocarps: an ideal study system}

To evaluate the predator satiation hypothesis and other hypotheses proposed for the evolution of mast fruiting, the Bornean dipterocarp masting community was selected for five main reasons. First, dipterocarp mast fruiting is much more extreme (longer intervals, tighter fruit drop, and strict mast fruiting) and is more highly synchronized (across hundreds of species and widely dispersed sites) than has been observed for temperate mast-fruiting species (Curran 1994). Thus, we would predict selective regimes to be pronounced and easily detected. Second, rapid germination is concurrent with fruit fall (i.e., no seed bank), and optimal periods for germination can be precisely quantified. This contrasts with many temperate species, which display delayed germination. Third, sympatric dipterocarp species possess seeds that vary greatly in mass. Sork (1993) proposed that seed mass may influence Quercus mast-fruiting cycles. Fourth, reproductive adults of many species occur across diverse soil types along an altitudinal gradient and at many levels in the forest strata (understory, mid-canopy, canopy, or emergent). Thus, variability in resource accumulation and investment in seed crops can be examined with reproductive synchrony. Fifth, unlike the majority of temperate mast-fruiting species that are wind pollinated, dipterocarp species are insect pollinated (Chan 1977, 1981, Chan and Appanah 1980), stagger flowering times among species groups that share pollinators (Appanah 1990, Yap and Chan 1990, LaFrankie and Chan 1991), and the communitywide reproductive response includes species and genera 
that do not share pollinators. Flowering is asynchronous and, thus, mast fruiting in this community has not evolved solely to promote outcrossing or to enhance pollination success.

Dipterocarp seeds are exclusively wind or gravity dispersed. Dipterocarp mast fruiting does not involve complex interactions of vertebrates that destroy some seeds but also provide dispersal services. Unlike temperate oaks (Quercus), some pines (Pinus), and beech (Fagus), dipterocarps are not subjected to conflicting pressures to produce seeds to maintain disperser populations. Dipterocarp seeds are eaten only by predators that impart directional (negative) selection, rather than the more complex web of relationships (positive and negative selection) found in temperate communities.

\section{Dipterocarp seed predation and tests of predator satiation}

The predator satiation hypothesis is not adequately tested by examination of whether or not dipterocarps experience high levels of successful seed dispersal and seedling recruitment in a mast year (e.g., Medway 1972). Would individuals experience comparable levels of seed predation and recruitment if reproduction were less synchronized among dipterocarp species, or if masting occurred more frequently?

Opportunistic observations that some insects or vertebrates feed on dipterocarp seed do not bear decisively on this hypothesis either, unless the predation is intense and extensive across many dipterocarp species when a large amount of dipterocarp seed is ripened within a habitat or region. High predation levels, or even complete crop failure (from pre-dispersal insects) when isolated dipterocarp individuals or even a single population fruit, have also been offered as support for the predator satiation hypothesis (Burgess 1975, Chan 1980). These cases, however, cannot predict that high seed mortality would occur across many populations if they were to fruit synchronously and annually, or at least more frequently. These examples are relevant to intrapopulation synchrony, but cannot address why many populations fruit together after long intermast intervals. Many tropical tree populations incur high levels of pre-dispersal and post-dispersal seed predation, yet they do not display mast fruiting or synchronize reproduction with other species (e.g., Dipteryx panamensis, De Steven and Putz 1984; Virola surinamensis, Howe et al. 1985; Lauraceae spp., Wheelwright 1985, 1986; Gustavia superba, Sork 1987; Faramea occidentalis, Schupp 1987, 1988, 1990).

\section{Dipterocarp reproduction and the controversial role of vertebrate seed predators}

A few published accounts contain scattered, opportunistic observations of vertebrates eating dipterocarp seeds, and foresters' lore or forest-dwelling peoples' reports link the massive regional migrations or lemming-like population eruptions of the bearded pig (Sus barbatus) to dipterocarp mast fruiting (Shelford 1917, Banks 1931, Anonymous 1953, Pfeffer 1959, McClure 1966, Janzen 1974, Caldecott and Caldecott 1985, Caldecott 1986, Pfeffer and Caldecott 1986). In Peninsular Malaysia, Medway (1972) recorded two mast-fruiting events in 1964 and 1969, but he did not observe any vertebrates eating dipterocarp seed. This contradiction led Janzen (1974, 1978, Janzen and Vázquez-Yanes 1991) to conclude that regional vertebrate communities were already decimated as early as 1966 .

Contrary to Janzen's predictions, Chivers (1980 in Johns 1988:35; also reported in Whitmore 1984, Johns 1992) stated that "Dipterocarps, the main timber trees extracted in southeastern Asian forests, are almost entirely unused by animals as food sources." The absence of empirical studies can be attributed to three main difficulties in monitoring dipterocarp mast fruiting: (1) the lack of predictability in fruit set and reproductive response (Harper 1977, O'Dowd and Gill 1984); (2) the long intermast intervals, coupled with limited ability to mobilize researchers and resources; and (3) the paucity of large, contiguous forested areas with undisturbed vertebrate faunas.

Two decades of forest conversion and exploitation have passed since Janzen (1974) remarked that the predator satiation hypothesis may be extremely difficult to examine due to habitat destruction, extensive commercial logging, and over-hunting of vertebrates. In contrast to Peninsular Malaysia, where all previous phenological studies on mast-fruiting dipterocarps have been conducted (McClure 1966, Medway 1972, Chan 1977, 1981, Chan and Appanah 1980, Appanah 1990, Yap and Chan 1990, LaFrankie and Chan 1991), large, contiguous tracts of dipterocarp forests remain intact in Kalimantan (Indonesian Borneo), where human population densities and hunting pressures on vertebrates are low.

West Kalimantan (Indonesian Borneo) is largely undisturbed and supports an intact seed predator guild, including large roosts of the now-rare Long-tailed Parakeet, Psittacula longicauda. The study area encompasses a vegetational mosaic that is necessary to examine the seasonal movement of nomadic vertebrates and the spatial scale of dipterocarp reproductive response (Fig. 1). During the study period, considerable variation in dipterocarp reproduction created a natural "experiment" that permitted a direct examination of mast fruiting as a reproductive strategy.

\section{Methods}

\section{Research region and site}

West Kalimantan Province.-This study was conducted primarily in the Gunung Palung National Park in West Kalimantan, Indonesia. Despite being Indonesia's third largest timber producing province, West Kalimantan (total area $146760 \mathrm{~km}^{2}$ ), as of 1989, had the lowest official percentage $(32.5 \%)$ of logged forests 


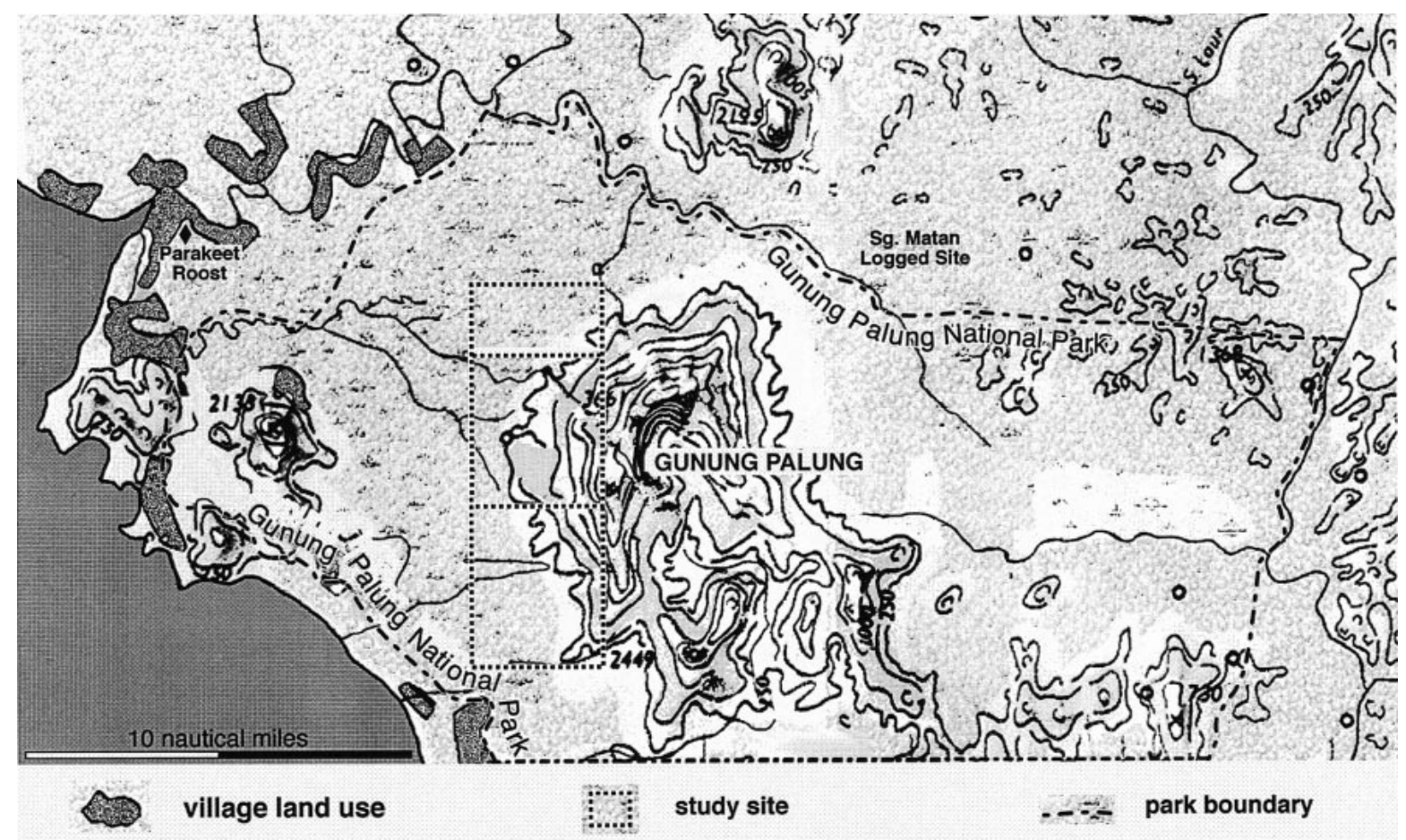

FIG. 1. Topographic map of Gunung Palung National Park, West Kalimantan. The 90000-ha national park $\left(1^{\circ} 00^{\prime}-1^{\circ} 20^{\prime}\right.$ S, $109^{\circ}-110^{\circ} 25^{\prime} \mathrm{E}$ ) is $\sim 130 \mathrm{~km}$ south of the capital city of Pontianak. The central box represents the main study area, with adjacent boxes indicating valleys surveyed for mast-fruiting response during the 1986, 1987, and 1991 mast events. The shaded areas near the coast are villages with cleared forest or agricultural areas. The location of the parakeet roosts in coastal mangrove forest is also noted. For the scale, 1 nautical mile $=1852 \mathrm{~m}$.

compared with all other dipterocarp mast-fruiting regions of Kalimantan and Sumatra (Indonesian Forestry Department 1991). West Kalimantan is $25.8 \%$ below the national average for the relative amount of logged forests within a province.

Gunung Palung National Park.-The Gunung Palung National Park (90000 ha; $1^{\circ} 00^{\prime}-1^{\circ} 20^{\prime} \mathrm{S}, 109^{\circ}-$ $110^{\circ} 25^{\prime} \mathrm{E}$ ) is adjacent to the southwest coast of Borneo, $130 \mathrm{~km}$ south of the provincial capital, Pontianak. Established as a protected area by the Dutch in 1929, the nature preserve's status was upgraded to a national park in 1989. This park contains a vegetational mosaic composed of riparian and mangrove forests along the coast, peat swamp forest overlying white sand deposits, freshwater swamp forest, mixed lowland dipterocarp forests consisting of alluvial bench deposits near streams and rivers, granite-derived podzolic soils along ridges, and in valleys, more fertile sandy-clay soils derived from sedimentary rock, along with upland submontane $(400-800 \mathrm{~m})$ granite forest formations. There is a pronounced cloud/montane forest at relatively low altitude (800-1100 m) due to the Massenerhebung effect on these coastal hills (Whitmore 1984). Thus, the reserve constitutes an extensive protected area with a diversity of vegetation types essential for evaluating dipterocarp community synchrony and large-scale vertebrate ranging patterns.

The park and main study area are two days by canoe from the nearest village. No people live within the core area of the reserve (90\% of the region), and population pressure surrounding the park is low. Sport hunting is not conducted anywhere in the region. The majority of resident peoples are coastal Islamics of Malay descent who do not hunt wild boar or other game because of religious prohibitions. Land cultivation has not been reported within the park.

The Gunung Palung National Park contains a full complement of all Bornean vertebrates except the rare and highly endangered herbivore, the Sumatran rhinoceros (Dicerorhinus sumatrensis), which has been virtually exterminated throughout Borneo (Payne et al. 1985). Endangered, protected, rare, and/or endemic Bornean species, such as the clouded leopard (Neofelis nebulosa), the marbled cat (Felis mamorata), the bay cat (Felis badia), the reticulated python (Python reticulatus), the Malaysian sun bear (Helarctos malayanus), the proboscis monkey (Nasalis larvatus), the orangutan (Pongo pygmaeus), the Argus Pheasant (Argusianus argus), the Long-tailed Parakeet (Psittacula longicauda), and the tufted-eared ground squirrel 
(Rheithosciurus macrotis), frequently have been sighted in the park.

At the onset of this study, there was no evidence of any dipterocarp extraction within the extended research area. As in the majority of sites across Kalimantan, low-impact hand extraction of large Bornean ironwood trees (Eursideroxylon zwageri Teijsm. \& Binnerd, Lauraceae) occurred in the park $\sim 80-100 \mathrm{yr}$ ago with some recent cuts in the mid-1980s. In 1989, rare scattered trees (Aquilaria malaccensis Lam., Thymelaeaceae) suspected of containing valuable incense resins (gaharu) were hand cut on site. Otherwise, forests and their animal communities remain undisturbed. A list of Dipterocarpaceae in Gunung Palung National Park is provided in Appendix A.

Study site.-The Cabang Panti Research Station was established within the Gunung Palung National Park in March 1985 and field studies presented here were conducted until January 1993. This site experiences an aseasonal climate with a mean annual rainfall of 4500 $\mathrm{mm}$ and an average daytime temperature of $32^{\circ} \mathrm{C}$. The $15-\mathrm{km}^{2}$ study area includes $>60 \mathrm{~km}$ of labeled trails forming a grid throughout the vegetational formations. The Air Putih river divides the two mountain regions of Mt. Panti $(1100 \mathrm{~m})$ and Mt. Palung $(1080 \mathrm{~m})$. The study area encompasses the two major ridge systems allowing a matched comparison across two distinct valley-montane complexes. During mast-fruiting events, surveys to the north and south of the study area expanded the region sampled to include four montanevalley sites.

Three mast-fruiting events occurred during the 82 field months of this study. This investigation encompasses two major and one minor interspecific mastfruiting event and spans one full intermast interval.

\section{Spatial and temporal pattern of dipterocarp reproduction}

Density and distribution of reproductive dipterocarps.-Seven vegetation types were surveyed across the 5-1100 m (a.s.l.) altitudinal and soil fertility gradient. In each vegetation zone throughout the $15-\mathrm{km}^{2}$ study area, we established 121 plots $(100 \times 30 \mathrm{~m})$. Plots were randomly drawn among the trail segments stratified by vegetational formations $(\geq 100 \mathrm{~m}$ apart to ensure independence). We recorded the diameter, condition, and species of all canopy dipterocarps $(>29 \mathrm{~cm}$ $\mathrm{dbh}$ ). In selected understory dipterocarp species ( $\mathrm{Ho}$ pea spp., Vatica spp., and Shorea multiflora), which reproduce at small sizes, the diameter at breast height (dbh) limit was lowered to $>9 \mathrm{~cm}$ dbh. The seed crops at each fruit maturation stage were assessed by estimating numbers in the crown and on the ground. Additional individuals, especially of rare species, were monitored along trails to increase sample size of large reproductive adults, but these individuals were excluded in the density calculations.

A total of 36.3 ha was examined at least semi-month- ly for reproductive activity of all trees $>29 \mathrm{~cm} \mathrm{dbh}$ during each mast event, and a subset of 21 ha was monitored at least monthly from 1985 to 1993. An additional 10.4 ha of phenological plots $(50 \times 30 \mathrm{~m}$; $n=69$ ), in which all individuals $>1 \mathrm{~cm}$ dbh were observed as part of the continuous, long-term sample of all tree and lianas, were also monitored monthly for reproductive activity. Over 2367 reproductive adults in 54 dipterocarp species (five genera) were sampled at the site.

Temporal pattern of fruit fall.-The temporal pattern of viable dipterocarp seedfall for the 1987 and the 1991 major mast events was documented using fruit fall traps (Curran 1994). The "minor" mast in 1986 required a different sampling regime, due to the patchy distribution of reproductive individuals and heavy pre-dispersal seed loss. Density and basal area of reproductive individuals were quantified in plots and individual crop sizes were estimated weekly. Crop size was quantified by counts of a portion of crown and was then multiplied by the approximate volume of the crown with an exponential scale (Leighton 1993). Trees were scanned with binoculars $(10 \times 40)$ to determine if they were reproductive, the stage of fruit maturity, and to estimate crop size (number of fruit per individual crown). We estimated fruit numbers in sample units of canopy volume or surface, or of individual twigs or branches, dispersed around the crown. We then determined the total crop size by multiplying this mean number of fruits by the number of sample units. Crop size was estimated on an exponential scale, in which each order of magnitude was divided into three equal-sized classes (e.g., 1-3, 4-7, 8-10; 11-39, 40-69, 70-99; 100-399, $400-699,700-999 ; 1000-3999, \ldots$ fruits $)$. The median of the class was used as a point estimate in analysis. To ensure replicability, Curran estimated the great majority of the crop sizes and inter-observer reliability tests were performed to scale the other two observers to her values. Ground crops also were assessed to determine the proportion of seeds in each maturation stage and damage type. Several transects (4-6) from the bole of each reproductive individual were surveyed and $1-\mathrm{m}^{2}$ counts at standard intervals $(5 \mathrm{~m}, 10 \mathrm{~m}, 15$ $\mathrm{m}$ to $40 \mathrm{~m}$ ) were recorded. Exact seed counts by damage type, by agent, and by maturity stage were included in these subsamples. These counts were then standardized by distance from the bole and weighted by the area included in concentric circles to encompass the entire seedfall area. Approximate seed production and loss to vertebrates per individual tree were calculated to yield seed density per hectare. Inter-observer reliability tests were performed to standardize values.

Frequency, intensity, and spatial scale of dipterocarp mast events in GPNP and across West Kalimantan.-Across the province of West Kalimantan, illipe nut export records were compiled as a baseline index for the relative frequency and intensity of mast events in the region. Illipe nut is produced by $\sim 5-10$ large- 
seeded Shorea species, primarily in section Pachycarpae, endemic to Borneo (Ashton 1982). Because nomadic vertebrate seed predators range considerable distances, regional production is an appropriate measure to assess relative seed availability. Furthermore, the illipe export figures also allow an assessment of the relative intensity of mast events monitored in this study with regional production over the last $29 \mathrm{yr}$. Yet, illipe export figures may be imprecise for several reasons. These figures combine all seed from 5-10 Shorea spp. gathered across a $120000-\mathrm{km}^{2}$ area. Northeast regions may be out of synchrony with southwestern regions. Economic factors that influence gathering as well as transport and storage of dried illipe seeds may affect the amount and arrival of seed to the port and may be recorded in the following fiscal year. Almost all illipe nuts are gathered from natural forest areas, although some scattered sites of a few thousand hectares $(<5000$ ha) are under local cultivation (Tantra 1977).

During the peak fruit fall in all three mast events, valley systems $\geq 3 \mathrm{~km}$ to the north and south of the research site were surveyed to determine whether dipterocarp phenology in nearby regions was similar to GPNP and whether nomadic vertebrate seed predators were in these areas. During the 1991 mast event, phenological studies of dipterocarps $\sim 30 \mathrm{~km}$ to the northeast of the GPNP research station ( $\mathrm{Sg}$. Matan region) were monitored simultaneously with the GPNP populations (Fig. 1). Further, in 1991-1992, selected forest sites throughout the province were examined to determine if a dipterocarp mast fruiting had occurred and to assess dipterocarp seedling regeneration.

\section{Vertebrate responses to dipterocarp seed production}

To assess vertebrate foraging and ranging patterns, the research team employed vertebrate censuses, focaltree watches, and vertebrate follows.

Censusing vertebrates.-Vertebrate censuses were conducted on trails or transects distributed throughout the seven vegetational formations. Four-hour census routes (0530-0930) within a habitat were used to calculate relative vertebrate densities by standardizing times and pairing routes. Two to six routes typically were followed daily, matched across both mountainvalley complexes. Only independent sightings of vertebrates were used. Upon detection of vertebrate(s), the following information was recorded: distance from trail, activity, age, sex, and group size of animals. Food type, patch time, feeding rate, and maturation stage of fruit or seed also were collected if appropriate. Food trees were tagged, their location was recorded, and botanical specimens were prepared.

To examine relative densities and social structure, we quantified the number of independent sightings along with group composition (age, sex, reproductive condition of individuals) per 4-h census. Temporal and habitat differences in total sampling times were standardized by expressing vertebrate abundances as rates of encounter per hour averaged over each month. Because individuals could not be readily distinguished and groups could not be marked, absolute densities were not calculated. These data, however, yield reliable figures of relative abundance and major changes in vertebrate distribution, as well as unbiased feeding observations.

Focal tree observation.-During the mast-fruiting episodes, the research team employed focal tree watches to establish feeding group size, feeding rates, and patch residency time. We observed that vertebrates typically fed actively between two periods; thus, we scheduled focal tree watches from 0530 to 0930 and 1600 to 1900 . Observers were hidden from animal view. These data are not included in assessments of ranging or habitat use, but are used to obtain species-specific feeding observations, especially of birds that often were disturbed by moving researchers.

We recorded the following information, using only independent sightings of individuals: the number of animals feeding in a patch, the average individual and group residency times, crop size when vertebrates entered and departed a patch, and handling times for selected focal animals. After observing arboreal feeding, we surveyed ground transects from the tree bole throughout the fruit fall area to establish approximate seed loss. Biomass of seed destroyed by arboreal predators was determined by multiplying seed counts (per $1 \mathrm{~m}^{2}$ ) by species-specific dry seed masses. With terrestrial predators, the rate of seed intake could not be quantified. In some cases, however, absolute counts were made.

Following vertebrates.-Censuses, tree watches, and follows of vertebrate seed predators, primarily parakeet flocks and primates, were conducted simultaneously. Because birds traveled in noisy groups and often circled many times before landing in crowns, observers were able to follow the flock between patches and locate groups. Long-tailed Parakeet (Psittacula longicauda) foraging data were converted to the number of bird feeding minutes per bout and then standardized per observation hour. From this, an average number of trees visited per hour was obtained. Given that groups splinter and stay in different patches for varying lengths of time, bird feeding minutes per hour is the best measure for assessing foraging pressure. These data allowed us to calculate the number of tree visits per morning or evening feeding period and to quantify generalized feeding across many dipterocarp species. The speciesspecific handling time for each dipterocarp species was multiplied by the number of bird feeding minutes observed in each dipterocarp crown. We tagged these trees and returned to assess damage, seed loss, and spatial location of foraging groups.

\section{Analyses}

Randomization contingency tests (1000 or 10000 runs) were applied to test several null hypotheses: (1) 
FIG. 2. Relative proportion (mean $\pm 1 \mathrm{SE}$ ) of Dipterocarpaceae in the total canopy basal area $\left(\mathrm{m}^{2}\right.$; trees $\left.>49 \mathrm{~cm} \mathrm{dbh}\right)$ across six forest formations with non-dipterocarp canopy trees. This sample is based on 96 0.33-ha plots (936 trees) distributed across peat swamp, freshwater swamp, alluvial raised bench, sandstone, lowland granite, and upland granite forest types from 5 to $900 \mathrm{~m}$ a.s.l (above sea level). The peat swamp formation (a) contains a significantly lower proportion of dipterocarps than all other forest formations, and the swamp (b) contains a significantly lower proportion of dipterocarps than all other forest types except peat swamp $(P<0.05)$. The lowland granite formation (d) contains a significantly greater proportion of dipterocarp basal area than do all other formations $(P<0.05)$. All other pairwise comparisons (c) are nonsignificant $(P \geq 0.05)$.

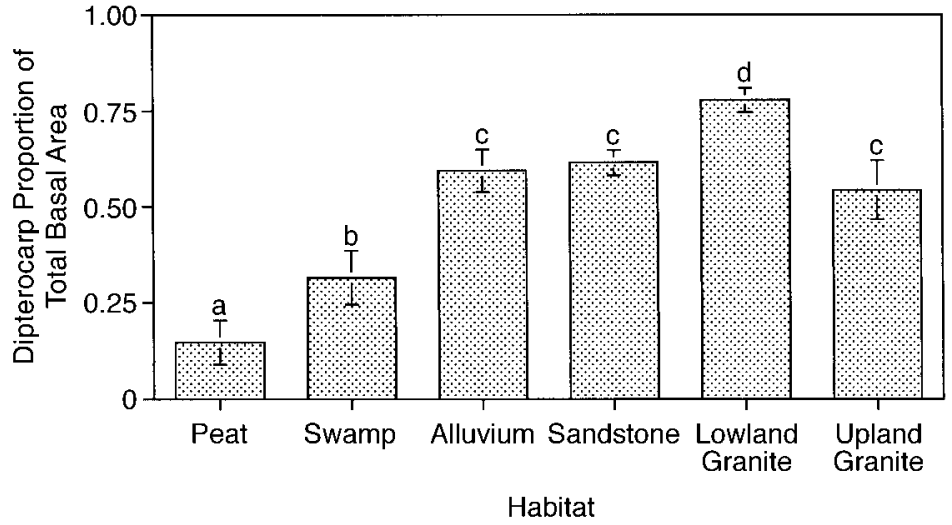

2. Intraspecific fruiting.-A common lowland species $\left(0.84 \mathrm{~m}^{2} /\right.$ ha adults $>49 \mathrm{~cm}$ dbh $)$, Shorea lamellata (section Anthoshorea), fruited in intraspecific synchrony, but 2-6 mo before the major community mast in the two events of 1986 and 1990. In 1986, 90.2\% of this monitored adult population (47 of 53) attempted to disperse seed. In $1990,51 \%$ of the basal area of the adult lowland population $\left(0.43 \mathrm{~m}^{2} / \mathrm{ha}\right)$ matured seed. In both years, some $S$. lamellata individuals managed to escape destruction by insects, although there was high infestation by weevil larvae (Curculionidae, Alcidodes curvirostris Lyal sp. nov.; and Apionidae, Nanophyes spp.) and Microlepidoptera (primarily Toricidae). The moths were found in seeds from the majority of mast-fruiting dipterocarps. These weevil species also attack other Anthoshorea hosts that reproduce during major mast events (e.g., S. virescens, S. gratissima). Reports confirm that $S$. lamellata again was reproductive well outside the community mast prior to a 1995 minor mast-fruiting event (C. O. Webb, personal communication).

For some species in the genus Vatica, it is more problematic to define participation in the mast fruiting. Most species were observed to reproduce only in major mast events. Two exceptions of more frequent fruiting were recorded at GPNP. Vatica umbonata (on river banks and occasionally flooded alluvium) and Vatica cf. granulata (of the upper montane; 900-1000 m a.s.1.) reproduced out of synchrony with the community mast. $V$. umbonata reproduction is episodic, but a portion of the $V$. cf. granulata population fruits annually.

Although individuals of one species, Vatica oblongifolia oblongifolia, occasionally reach canopy size $(>39 \mathrm{~cm} \mathrm{dbh})$, Vatica spp. primarily occupy the understory and midcanopy strata. Both nonmasting Vatica species are confined to specialized habitats and reproduce as small understory trees $(10-28 \mathrm{~cm}$ dbh). Neither has winged fruits. Flood waters provide secondary transport of $V$. umbonata, whereas $V$. cf. granulata may disperse by gravity on ridge areas. 
V. umbonata is extremely rare; nine adults (dbh 18.8 $\pm 2.1 \mathrm{~cm}$, mean $\pm 1 \mathrm{sE}$; range $10-28 \mathrm{~cm}$ ) were found on five different stream beds after an intensive search throughout a 3000-ha area. V. cf. granulata is locally gregarious $(37.3 \pm 7.8$ individuals/ha, mean $\pm 1 \mathrm{SE}$; $n=11$ plots) on extremely poor soils and granite outcroppings on exposed slopes above $900 \mathrm{~m}$ a.s.l. These montane species also reproduce at small sizes (dbh 12.8 $\pm 0.7 \mathrm{~cm}$, mean $\pm 1 \mathrm{sE} ; n=41)$. Both species incur high weevil infestation, caused primarily by Alcidodes vaticus Lyal, sp. nov. (Lyal and Curran 2000). Observations of vertebrate seed predation were not recorded on either of these Vatica species in any reproductive event.

3. Interspecific mast fruiting.-In 1986, a localized minor mast occurred primarily in the fertile alluvial, freshwater swamp, and sandstone forest formations
(Fig. 3, Table 1). Lowland forests in at least four valley systems spanning $\sim 12 \mathrm{~km}^{2}$ also participated. Only one Dipterocarpus individual (out of 183 canopy trees) was observed to flower during this minor event. Although a few Hopea individuals were reproductive, the minor mast participants primarily were Shorea species. The reproductive response occurred across all five sections of Shorea and six of the seven vegetation types within the site. The percentage of the known adult populations that matured seed varied considerably among species. Generally, large individuals in these populations fruited in 1986.

Twenty-one dipterocarp populations synchronized reproduction, with $30.8 \%$ of the lowland basal area of adult individuals responding to the minor event. Nine common lowland Shorea species (3.7 trees/ha) matured large crops (59891 seeds/ha with seed dry mass of 46.2

\section{Reproductive 8 Nonreproductive}
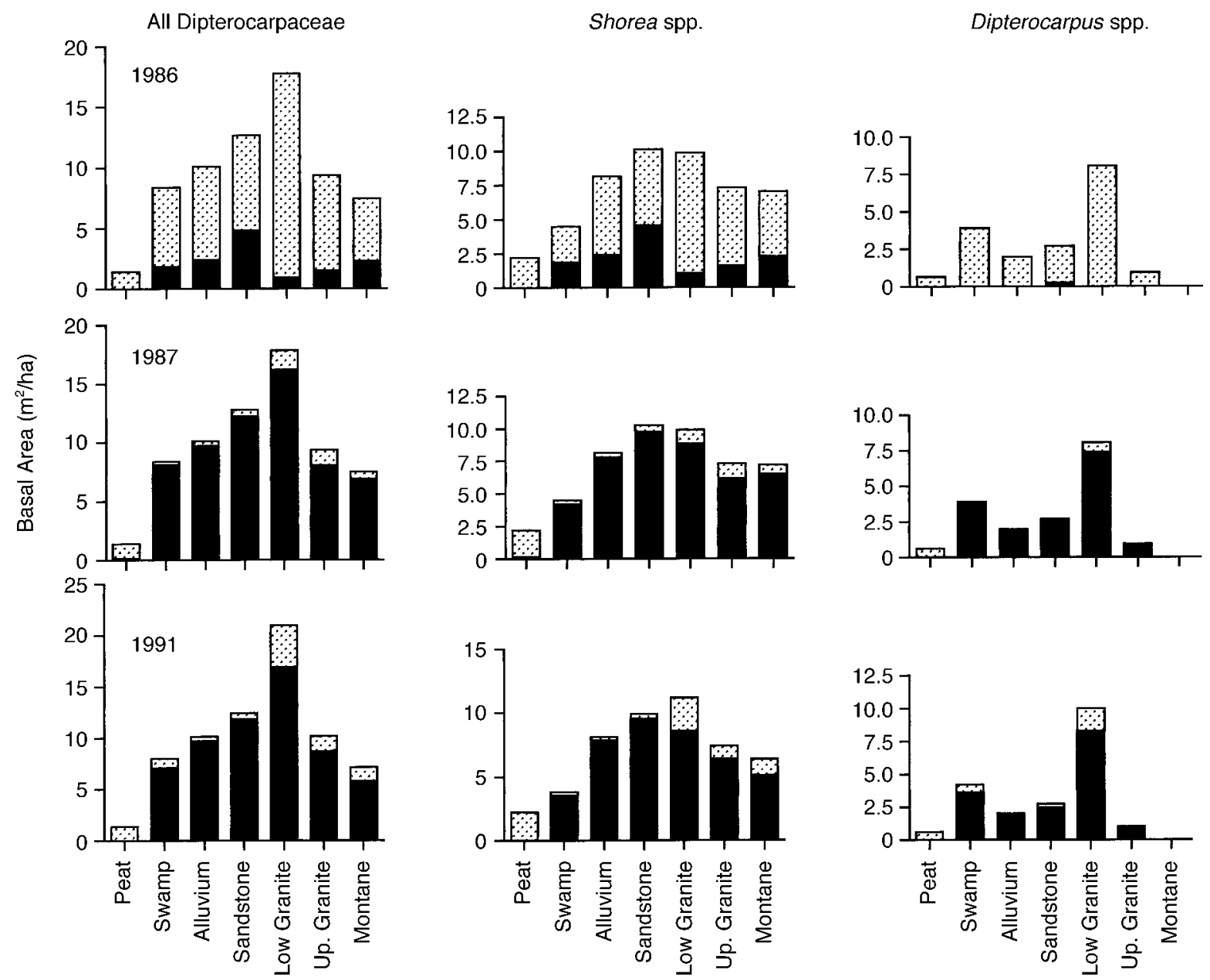

Forest Formations

FIG. 3. Reproductive response of canopy dipterocarps in seven vegetation zones for the 1986, 1987, and 1991 mastfruiting events. The phenology sample presented includes 782 trees from 41 species in 1210.33 -ha plots totaling 36.3 ha. Canopy dipterocarps are $>49 \mathrm{~cm}$ dbh in all habitats except upland granite $(>39 \mathrm{~cm} \mathrm{dbh})$ and montane $(>29 \mathrm{~cm} \mathrm{dbh})$. 
$\mathrm{kg} / \mathrm{ha}$ ). Although $\sim 60 \%$ of this mature seed was destroyed by pre-dispersal insects, over $>18 \mathrm{~kg} / \mathrm{ha}$ of seed (dry mass) ripened in lowland sandstone and alluvial forests.

Two major regional dipterocarp mast events were recorded 1987 and 1991. All 51 dipterocarp species (except the asynchronous $S$. lamellata and the two understory Vatica spp.) participated in these fruiting episodes. Reproduction was observed across all forest types, from lowland swamps to upper montane regions (Fig. 3). In 1987, 88.2\% of all canopy Shorea individuals and $93 \%$ of all canopy Dipterocarpus individuals ripened seed across all forest types except the peat swamp. A similar reproductive response was recorded in 1991 , when $84 \%$ of all adult individuals of Shorea spp. and $79.6 \%$ of all Dipterocarpus adults participated in the fruiting event (Fig. 3). Table 1 summarizes all dipterocarp reproductive events and seed availablity, with vertebrate response, for March 1985 through January 1993.

From these observations, the minor 1986 mast event appears to be a miscue; early-flowering species (e.g., Shorea pinanga, S. macrophylla) responded, whereas species that flower later in the temporal sequence did not begin to flower (e.g., S. laevis, S. leprosula; L. M. Curran, unpublished data). All Shorea sections responded in the 1986 minor mast. Although concentrated in the lowlands, Shorea crassa and S. gratissima individuals in both the lowlands and upper elevations (>800 m a.s.1.) matured seed. Only 1-2 mo after the 1986 minor mast, $89.4 \%$ of the individuals that ripened crops began to flower and matured seed in the JanuaryMarch 1987 mast.

Spatiotemporal scale of dipterocarp mast-fruiting events in West Kalimantan.-By compiling forestry export records of illipe nut (Shorea sect. Pachycarpae) for the province of West Kalimantan, we determined the frequency of "good" mast production years $(>5$ $\left.\times 10^{6} \mathrm{~kg}\right)$ along with "bumper" crop $\left(>10 \times 10^{6} \mathrm{~kg}\right)$ years. A "bumper" crop occurred every five years (5.0 $\pm 2.6 \mathrm{yr}$, mean $\pm 1 \mathrm{SD}$; range $3-9 \mathrm{yr}$ ); a good year occurred every three years $(3.3 \pm 1.5 \mathrm{yr}$; range $1-6$ yr). The records revealed many years without any seed exports $(\mathrm{CV}=152.4 \%$; Fig. 4).

Direct observations of dipterocarp reproductive behavior in and surrounding the region of the Gunung Palung National Park, near Sukadana and Ketapang, West Kalimantan, corroborate the provincial records of illipe nut export from 1984 to 1997. In March 1985, there was no evidence of dipterocarp regeneration from a major fruiting that would have occurred up to two years before our arrival. All other regeneration events recorded during this study $(1986,1987$, and 1991) coincide with regional export levels.

The 1987 and 1991 mast events recorded here rank third and fourth, respectively, as the largest recorded mast events since 1968. Also, the 1986 mast is a relatively minor event compared with these major masts.
Although minor by regional standards, 1986 dipterocarp seed exports were quite large when assessed in absolute terms $\left(1.98 \times 10^{6} \mathrm{~kg}\right)$.

To produce $1.98 \times 10^{6} \mathrm{~kg}$ of dried illipe seed in 1986, dipterocarp reproduction must have occurred across a considerable forest area, not just within Gunung Palung National Park (GPNP). Species that produce illipe nuts are only a small subset $(\sim 10 \mathrm{spp}$.) of the 257 described Bornean dipterocarps (Ashton 1982; see Appendix A). At GPNP, illipe species are most common in the sandstone forest, with an average of $0.6 \pm 0.5$ reproductive trees/ha (sampled over $3 \mathrm{~km}^{2}$ ). Assuming complete harvest of illipe seed production, estimates of crop size and dried seed mass yield approximately 4-9 kg/ha produced across lowland forest in major mast events. Therefore, the 1986 mast episode must have occurred over at least 225 000-495000 ha of West Kalimantan mixed lowland dipterocarp forest.

Between January 1991 and October 1992, selected forest sites across West Kalimantan were surveyed to assess if the dipterocarp community reproduced in the most recent mast event. All 15 surveyed sites contained copious recent dipterocarp regeneration. If forests between the visited areas also participated in the 1991 mast event, then the area encompassed is $>120000$ $\mathrm{km}^{2}$ (Fig. 5).

El Niño-Southern Oscillation (ENSO) and dipterocarp mast events. - The relationship between the magnitude of seed exported in West Kalimantan in documented El Niño-Southern Oscillation (ENSO) events vs. non-ENSO years was examined from 1968 to 1997 (Rasmusson 1985, Trenberth and Hoar 1996, Trenberth 1997; Fig. 4). Seed production in ENSO years (e.g., 1976-1977, 1982-1983) was significantly greater (6.73 $\pm 1.83 \times 10^{6} \mathrm{~kg}$, mean $\left.\pm 1 \mathrm{sE} ; n=14\right)$ than in nonENSO years $\left(0.96 \pm 0.43 \times 10^{6} \mathrm{~kg}, n=16 ; P>0.0005\right.$ from 10000 randomizations). If high seed production is defined as greater than the midpoint in the range of all yearly production values $\left(0-17.38 \times 10^{6} \mathrm{~kg}\right.$ or 8.69 $\times 10^{6} \mathrm{~kg}$ ), there are five ENSO years greater than the midpoint ( $P=0.0147$ from 10000 randomizations). If "high" seed production is conservatively defined as greater than the mean yearly production $\left(>3.65 \times 10^{6}\right.$ $\mathrm{kgs})$, then seven ENSO years are greater than the mean ( $P=0.0304$ from 10000 randomizations). Miscues or minor events usually directly precede ENSO years or immediately follow ENSO events.

\section{Vertebrate responses to dipterocarp seed production}

Dipterocarp vertebrate seed predators.-Of the 1004 independent vertebrate seed predator feeding observations during mast events, $>200$ were of vertebrates eating dipterocarp seed. All vertebrates destroyed ripe, or nearly ripe, dipterocarp seed from species with seed dry mass ranging from $0.15 \mathrm{~g}$ to $>10$ g. Six large-bodied arboreal vertebrate species were observed destroying dipterocarp seed: the giant arboreal squirrel Ratufa affinis, Prevosti's squirrel Callos- 
TABLE 1. Summary of dipterocarp reproduction at the Gunung Palung research site, Borneo, from March 1985 to January 1993.

\begin{tabular}{|c|c|c|c|c|}
\hline Reproductive event & Participants & Temporal pattern & $\begin{array}{c}\text { Spatial } \\
\text { distribution }\end{array}$ & $\begin{array}{c}\text { Reproduction } \\
\text { (\% of basal area) }\end{array}$ \\
\hline \multirow[t]{2}{*}{ Individuals ( $\sim 12$ cases $)$} & $\sim 6$ species & sporadic & scattered & $\cdots$ \\
\hline & S. gratissima & 1987-1992 & stressed trees & $\cdots$ \\
\hline Understory Vatica spp. & 2 populations & $\begin{array}{l}\text { irregular and } \\
\text { annual (?), } \\
1985-1992\end{array}$ & $\begin{array}{l}\text { rare, riverine; gregarious, } \\
\quad>900 \mathrm{~m} \text { a.s.1. }\end{array}$ & $\cdots$ \\
\hline \multirow[t]{2}{*}{$\begin{array}{l}\text { One common population, } \\
\text { intraspecific synchrony }\end{array}$} & S. lamellata & May 1986 & $\begin{array}{l}\text { lowlands, } 1.38 \text { adults } / \mathrm{ha} \\
\text { (basal area } 0.84 \mathrm{~m}^{2} / \mathrm{ha} \text { ) }\end{array}$ & 90.6 \\
\hline & S. lamellata & Apr 1990 & $\cdots$ & 40.0 \\
\hline $\begin{array}{l}\text { Minor mast, interspecific } \\
\text { synchrony }\end{array}$ & $\begin{array}{l}21 \text { species, mainly } \\
10 \text { Shorea spp. }\end{array}$ & Aug 1986 & $\begin{array}{l}\text { primarily }<200 \mathrm{~m} \text { a.s.1., } \\
\quad 3 \mathrm{~km}^{2}\end{array}$ & $\begin{array}{l}\text { lowland: } 30.8 \\
\text { all habitats: } 20.2\end{array}$ \\
\hline $\begin{array}{l}\text { Major mast, interspecific } \\
\text { synchrony }\end{array}$ & all 51 species & Feb-Apr 1987 & all habitats, $\dagger 15 \mathrm{~km}^{2}$ & 92.8 \\
\hline $\begin{array}{l}\text { Major mast, interspecific } \\
\text { synchrony }\end{array}$ & all 51 species & Feb-Apr 1991 & all habitats, $\dagger 15 \mathrm{~km}^{2}$ & 88.0 \\
\hline
\end{tabular}

Notes: Basal area, in square meters per hectare, includes trees with $\mathrm{dbh}>49 \mathrm{~cm}$. Variation around the mean is $1 \mathrm{sE}$ for number of seeds and seedlings.

$\dagger$ Except peat swamp forest, $15-1100 \mathrm{~m}$ a.s.1.

† In April 1991, $18941 \pm 3866$ seedlings/ha survived from the 1987 mast.

ciurus prevosti, the red leaf monkey Presbytis rubicunda, the crab-eating macaque Macaca fasicularis, the Long-tailed Parakeet Psittacula longicauda, and the orangutan Pongo pygamaeus. Opportunistic observations made by other field researchers in Malaysia and East Borneo revealed that the Plantain squirrel $\mathrm{Cal}$ losciurus notatus, the black-banded squirrel Callosciurus nigrovittatus, the blue-rumped Parrot Psittinus cyanurus, and the pig-tailed macaque Macaca nemenstrina also consume dipterocarp seeds (McClure 1966, Gould and Andau 1989; F. Sheldon, personal communication). This latter group of vertebrates is relatively rare; they were not observed feeding in the study area during the West Kalimantan mast events.

A diversity of terrestrial vertebrate predators fed on seed below dipterocarp crowns: the bearded pig Sus barbatus, Green-winged Pigeon Chalcophaps indica, Crested Wood Partridge Rollulus rouloul, Crestless Fireback Pheasant Lophura erythropthalma, Crested Fireback Pheasant Lophura ignata, red spiny rat Maxomys surifer, brown spiny rat Maxomys rajah, Whitehead's rat Maxomys whiteheadi, Muller's rat Sundamys muelleri, and the long-tailed giant rat Leopoldamys sabanus. The vertebrate seed predators at Gunung Palung are listed, along with their body mass and foraging ecology, in Appendix B.

Generalized seed predation.-The most common vertebrate seed predators were observed feeding on every species with ripe seed available. Parakeets and bearded pigs fed on as many as 23 dipterocarp species of five genera, whereas wood partridges destroyed seeds from $\geq 10$ dipterocarp species. Moreover, these dipterocarp species were attacked simultaneously. For example, during a single morning feeding bout, eight Shorea species were attacked by parakeets (Psittacula longicauda) and bearded pigs and wood partridges fed below the crowns, cleaning up any seeds missed.

During the three mast-fruiting episodes, scatterhoarders were not observed removing dipterocarp seed. Scatterhoarding squirrels (e.g., Sundasciurus hippurus and $S$. lowii) were observed dispersing seeds from other species such as Lithocarpus spp. (Fagaceae). In captive feeding trials, these seed-caching squirrels (S. hippurus and $S$. lowii) rejected all dipterocarp seeds (Gould and Andau 1989).

Resident and nomadic vertebrates.-Resident vertebrates maintain home ranges and/or territories within the study area, whereas nomadic vertebrates possess highly variable ranging patterns in both time and space (Spitz and Janeau 1995) that often extend beyond the boundaries of the $15-\mathrm{km}^{2}$ study region. Most of the residents are arboreal or pre-dispersal seed predators, and nomadic vertebrates are terrestrial post-dispersal seed predators. The Long-tailed Parakeet, however, attacks seed in the tree crown, but is deemed "nomadic" because flocks use the lowlands only during mast fruiting and travel long distances daily $(\sim 20 \mathrm{~km})$ from colonial roosts outside the national park (Fig. 1).

Although both resident and nomadic vertebrates destroyed a diversity of dipterocarp seeds, the timing of their impact differed significantly (Fig. 6.: 1986, $P<$ $0.0001 ; 1987, P<0.0001$, both from 10000 random- 
TABLE 1. Extended.

\begin{tabular}{|c|c|c|c|c|}
\hline $\begin{array}{l}\text { No. viable } \\
\text { seeds/ha }\end{array}$ & $\begin{array}{c}\text { Insect } \\
\text { infestation } \\
(\%)\end{array}$ & $\begin{array}{l}\text { Vertebrate } \\
\text { predation } \\
(\%)\end{array}$ & $\begin{array}{l}\text { Vertebrate } \\
\text { response }\end{array}$ & No. seedlings/ha \\
\hline none & 100 & 0 & none & none \\
\hline$\cdots$ & 98.8 & 1.2 & residents & none \\
\hline low $<15$ per tree & $\sim 80$ & $\cdots$ & none & $\ldots$ \\
\hline$\sim 27,000$ & $\sim 70$ & $\sim 30$ & nomadics & none \\
\hline $10464 \pm 8391$ & 64.2 & 34.3 & residents and pigs & none \\
\hline lowland: 59891 & $\begin{array}{l}\text { lowland: } \sim 60 \\
\text { upland: } \sim 98\end{array}$ & $\begin{array}{l}\text { lowland: } \sim 40 \\
\text { upland: } \sim 2\end{array}$ & $\begin{array}{l}\text { primarily nomadics; } \\
\text { some residents }\end{array}$ & none \\
\hline $\begin{array}{l}198000 \\
\pm 32120\end{array}$ & 43.2 & 1.5 & residents and nomadics & $\sim 95000 \ddagger$ \\
\hline $\begin{array}{l}247520 \\
\quad \pm 57680\end{array}$ & 53.5 & 2.6 & residents & $\begin{array}{l}155824 \\
\pm 36764\end{array}$ \\
\hline
\end{tabular}

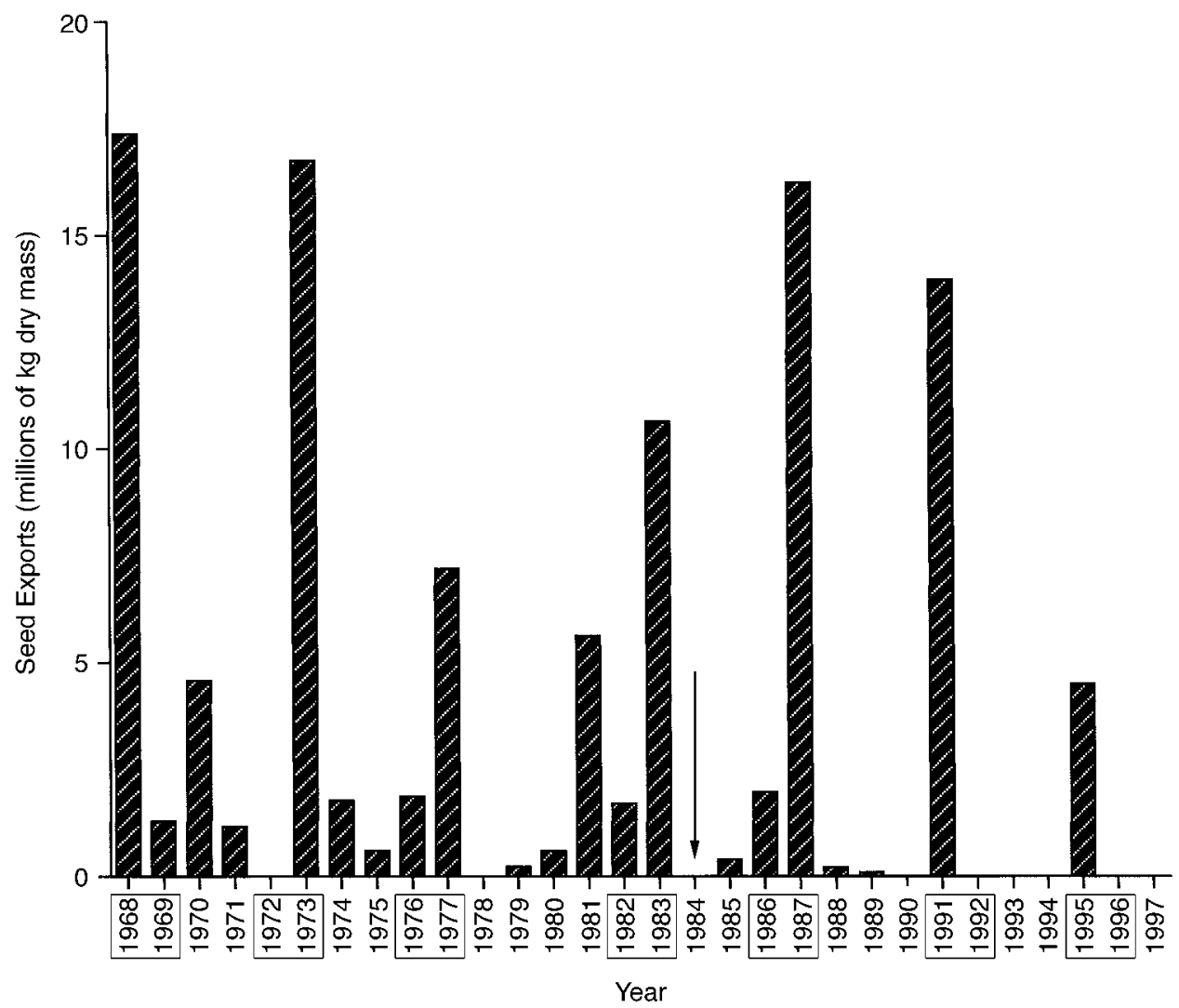

FIG. 4. The frequency and seed production of dipterocarp mast-fruiting events in West Kalimantan and their association with ENSO events, using export records of illipe nut (Shorea spp., section Pachycarpae) from 1968 to 1997. Export figures were adjusted from fiscal calendar records (April-Mar). ENSO years are in boxes. The coefficient of variation is $152.4 \%$. Seed production is significantly associated with ENSO years rather than with non-ENSO years $(P<0.0005$, from 10000 randomizations). The arrow indicates the onset of this field study. 


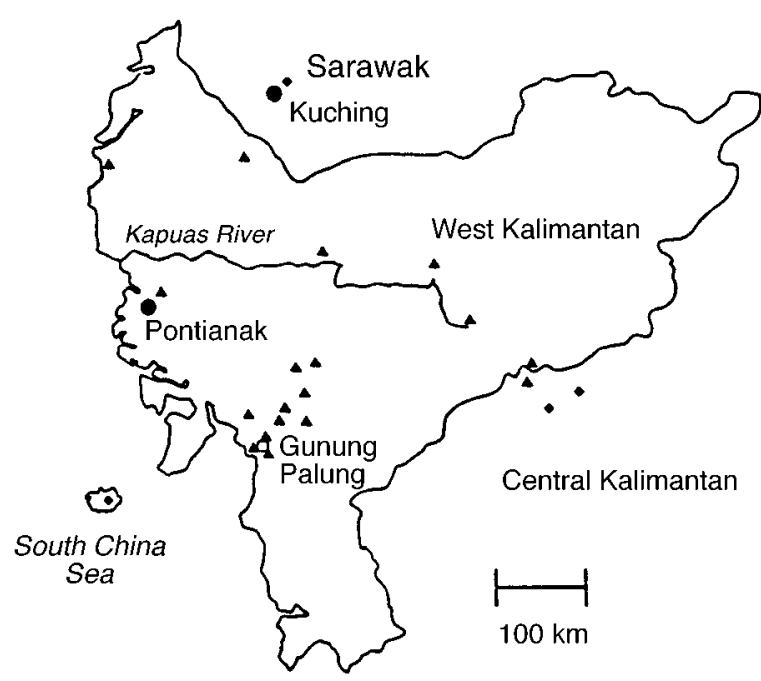

FIG. 5. Dipterocarp reproduction across West Kalimantan in the 1991 mast-fruiting event. Sites across the province (land area $146000 \mathrm{~km}^{2}$ ) were visited within 9 mo of the fruiting event, and dipterocarp seedling recruitment from the 1991 mast was recorded. The area covered that responded to the 1991 mast event is $\sim 120000 \mathrm{~km}^{2}$. Triangles indicate sites visited by L. M. Curran, and diamonds indicate sites reported by field researchers.

izations). Residents primarily attacked dipterocarp seeds early in the period of fruit fall. Residents clearly preferred non-dipterocarp species' seeds or fruit available during the mast-fruiting event, and fed on significantly fewer dipterocarp species (range 1-8 spp.) than nomadics (range 8-23 spp.; $P<0.0001 ; 10000$ randomizations).

Also, the relative importance of different seed predators changed in the 1986 and 1987 mast events. In 1986, resident squirrels (Callosciurus prevostii and Ratufa affinis) preyed on Shorea spp. seeds, whereas in 1987, primates (Pongo pygmaeus, Macaca fasicularis, and Presbytis rubicunda) preyed on seeds from Dipterocarpus spp. Fig. 7 displays the temporal pattern of arboreal resident seed predation (obtained from fruit fall traps) during the 1987 and 1991 mast events (Curran 1994). Both the amount and frequency of resident feeding on dipterocarp seeds were relatively low in all events. Thus, although resident vertebrate attacks were significantly associated with the tails of the fruit fall period, they did not have a strong negative impact on dipterocarp seed production in major mast years because other, more preferred, species also became available.

In contrast, nomadic vertebrates concentrated their feeding on dipterocarp seed. Feeding observations of nomadic vertebrates in the minor mast and the late tail of the 1987 major mast event indicated that dipterocarp seeds made up as much as $100 \%$ of their diet during this period. Moreover, the temporal pattern of attacks differed from resident vertebrates $(P<0.0001$, from 10000 randomizations). Nomadic vertebrates arrived late at the study site in both major mast events. In 1987, both bearded pigs and parakeets were first observed in the research area on 3 April and 8 April, respectively (Fig. 7). Similarly, in 1991, bearded pigs were first observed in the montane forest on 9 April, whereas parakeets were in the research area for only one or two days in mid-April. Thus, seed destruction by these nomadic vertebrates was concentrated on the late tail of dipterocarp fruit fall.

In both major mast events, when nomadic vertebrates arrived, few seeds remained either in the canopy or on the forest floor. In the 1987 mast, seed was dispersed 9 d later than the 1991 mast (Fig. 7). When nomadic vertebrates arrived in 1987, they destroyed a variety of species ( 7 species; 21 trees) still possessing small crops. In 1987, parakeets fed on an average of 11 trees per observation hour. For example, in $<10 \mathrm{~min}$ in 1987 ,

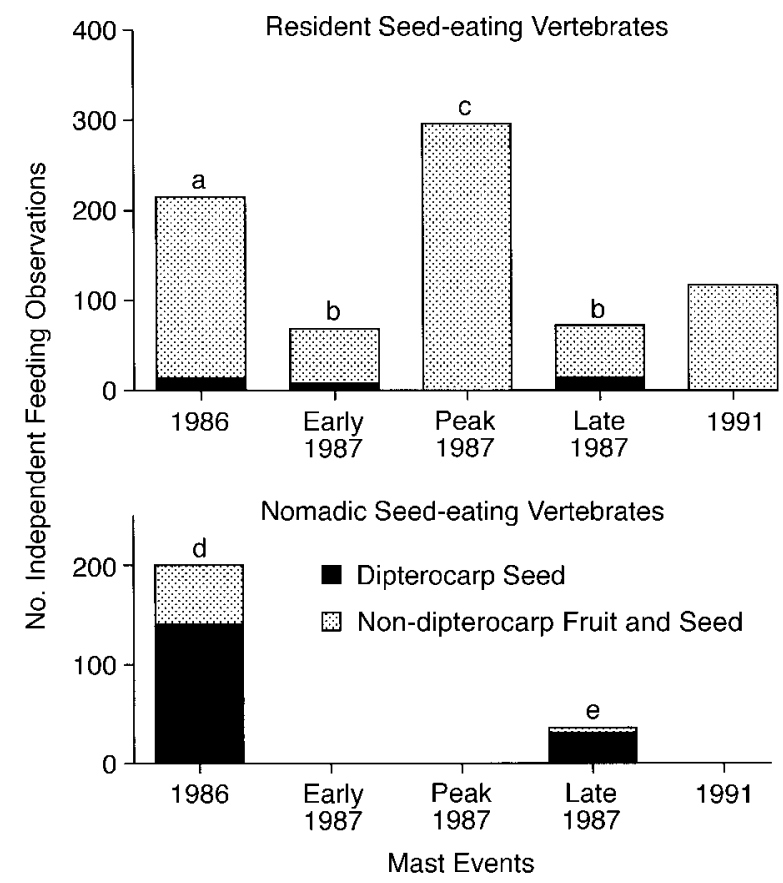

FIG. 6. Relative number of observations of dipterocarp seed in the diet of resident and nomadic seed-eating vertebrates, by mast event. In 1986, the period is $\sim 4 \mathrm{wk}$; in 1987, the bars represent three 4-wk periods: early, peak, and late. In 1991, nomadic vertebrates were absent from the site, and no observations of residents feeding on dipterocarp seeds were recorded. Samples were $n=768$ residents and $n=236$ nomadics. Resident vertebrates include only those observed to eat dipterocarp seed: Presbytis rubicunda, Macaca fasicularis, Ratufa affinis, Callosciurus prevosti, and Pongo pygmaeus. Nomadic vertebrates include Sus barbatus, Psittacula longicauda, Rollulus rouloul, and Chalcophaps indica. Nomadics ate significantly more dipterocarps (independent feeding observations) than did residents during the minor mast of 1986 and the tail of the 1987 mast (a vs. $\mathrm{d}$, $\mathrm{b}$ vs. e; $P<0.0001)$. Residents preyed on seeds during the tails of the 1987 seed distribution rather than the peak (b vs. c; $P<0.0001)$. There was no difference in the frequency with which residents fed on dipterocarp seed in the early or late tail in 1987 (b; $P=0.1606)$. All tests included 10000 randomizations. 


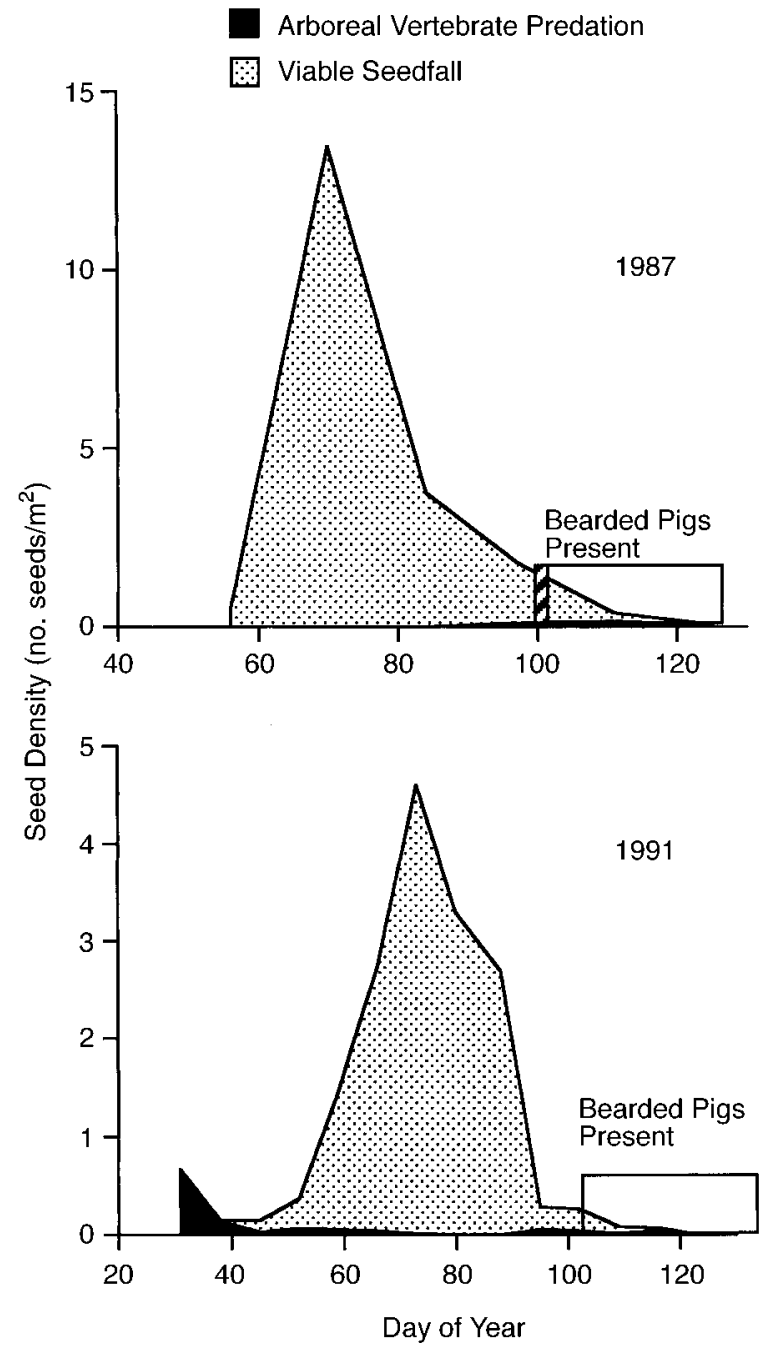

FIG. 7. The temporal distribution of seedfall in 1987 and 1991, with the timing of arboreal resident seed predation and presence of nomadic vertebrates. The striped bar indicates the presence of Long-tailed Parakeet. Seedfall was calculated from $483.06-\mathrm{m}^{2}$ seedfall traps (Curran 1994). Day 1 is 1 January.

parakeets attacked seven trees from six species. In 1991, however, nomadic vertebrates arrived after almost all dipterocarp seeds (with the exception of the late fruiting $S$. gratissima) were dispersed. In both major mast events, $100 \%$ of ungerminated, non-insect damaged seed in our samples was destroyed by nomadic vertebrates before they departed the research area.

Impact on dipterocarp seed crops. - The most significant predator was the Long-tailed Parakeet, Psittacula longicauda. Although foraging flocks fed in 1986 at GPNP, Long-tailed Parakeets were observed preying on dipterocarp seeds in valley systems to the north and south of the study area. In the 1986 minor mast, flocks visited several Shorea crowns in succession during their morning and late afternoon invasions.
In frenetic feeding bouts of a few to $22 \mathrm{~min}$, a flock $(51.9 \pm 8.1$ birds, mean $\pm 1 \mathrm{se} ; n=35)$ would destroy as many as 5000 Shorea seeds (391.3 \pm 91.9 seeds; $n$ $=13694$ bird feeding minutes). In a single visit to a tree crown, they would destroy $20-100 \%$ of an individual's crop. Flocks attacked an average of three trees per observation hour in 1986 (range: $1-5$ trees $/ \mathrm{h} ; n=$ 30 trees). Total bird feeding minutes per observation hour was extremely high: 1062 bird minutes or 20 feeding minutes per group per hour.

During the minor mast, parakeets were observed feeding in the lowlands from 1 August until 11 August 1986. Conservative estimates of dipterocarp seed (dry mass) observed to be destroyed in the canopy by parakeets were $1.02 \pm 0.38 \mathrm{~kg}$ seed $\cdot \mathrm{km}^{-2} \cdot \mathrm{d}^{-1}($ mean \pm 1 $\mathrm{SE})$.

Terrestrial predators keyed in on parakeet attacks, arriving at the fruit fall area a few minutes after the parakeets entered the tree crown. During $82 \%$ of the parakeet feeding bouts in 1986, bearded pigs fed below; $\sim 40 \%$ of our Crested Wood Partridge feeding observations were under trees where these parakeets fed. These are underestimates, because terrestrial vertebrates often displayed adverse reactions when aware of our presence in the area. Although some seed remained in crowns after parakeets left the area, all dispersed seed in our ground plot samples was devoured by the scavenging terrestrial predators.

Vertebrate response to dipterocarp seed availability.-The temporal sequence of fruit ripening is depicted with the relative densities of migrants before, during, and after the periods of dipterocarp seed availability from 1985 to 1992 (Fig. 8). Avian seed predator immigration was keyed to the dipterocarp seed maturation (Fig. 8). The parakeets and Green-winged Pigeons (Chalcophaps indica) were observed in mixed dipterocarp forest only when ripe dipterocarp seed was available. Terrestrial avian seed predators jungle fowl (Lophura spp.) and partridges (Rollulus rouloul) displayed patterns similar to those for arboreal parakeets, with concentrated sightings during the mast-fruiting events. Jungle fowl and partridges, however, were sighted occasionally during the intermast interval feeding on seeds of Fagaceae (Lithocarpus echinifer) and Lauraceae (Litsea spp.). In the 1986 minor mast, bearded pigs immigrated 1-2 mo earlier than the parakeets and ate seeds from early-ripening Alangium ridleyi (Alangiaceae) and Mangifera spp. (Anacardiaceae) before dipterocarp seeds were available. Bearded pigs were sighted sporadically during the intermast interval, often near non-dipterocarp trees with ripe fruit fall.

Patch choice, feeding bout length, and handling times.-Bearded pigs concentrated their foraging initially below crowns and later searched throughout an extensive forest area. They were efficient at locating even a few dipterocarp seeds. Consumption times were so brief that they were virtually impossible to quantify. For example, in a large-seeded Shorea species, the en- 
tire ground crop, $\sim 800 \mathrm{~g}$ of seed (dry mass), was ingested in $<5$ min on one occasion by one pig. When jungle fowl and partridges foraged together with pigs, we could not find any undamaged seed after they departed.

With arboreal predators, it was relatively easy to quantify the time spent in a patch, the amount of seed eaten per bout, and the consumption times for dipterocarp species. Parakeet handling times ranged from $<25$ $\mathrm{s}$ for Shorea parvifolia fruit (seed dry mass $0.4 \mathrm{~g}$ ) to 4 min for $S$. macrophylla (seed dry mass $8 \mathrm{~g}$ ). Parakeets rejected insect-damaged seed. Prevost's squirrel, Callosciurus prevostii, and the Giant squirrel, Ratufa affinis, sometimes fed in crowns with parakeets. Squirrel handling times all were $<1 \mathrm{~min} /$ fruit. In all cases, handling times were extremely brief and patch residence times reflected both the feeding group size and crop size. Predators typically left a patch only after the majority of available seed was depleted.

Food preferences during the mast event.-With other food sources available during the peak community mast, resident vertebrates ate dipterocarp seeds only during nonmast times or in the tails of the fruiting peak, when their preferred seeds or fruits were not available (Fig. 6). Even during the tails of the mast in 1986 and 1987, the percentage of dipterocarps in resident vertebrate diets (by vertebrate species) generally was $<33 \%$ dipterocarps, with only Callosciurus prevostii as an exception in 1986. In both the early and late tails of dipterocarp fruit fall in the 1986 and 1987 mast, for feeding by all resident vertebrates, the average percentage of dipterocarps in the diet was only $1.4 \%$ (Fig. $5 ; n=394$ feeding observations). Despite extensive surveys in 1987, not a single observation of residents feeding on dipterocarp seed was recorded during peak seedfall. Similarly, no dipterocarp feeding was observed during 4 wk of peak seedfall in 1991. In addition, fruit fall traps did not receive a single vertebrate-damaged seed during peak fruit fall in both major mast years: 1987 and 1991 (Fig. 7).

In contrast to residents, nomadic vertebrates concentrated their feeding on dipterocarp seed when available (Fig. 6). Although all nomadic vertebrates ate other available seed, dipterocarps made up the bulk of their seed intake. For example, captive parakeets readily ate small, hard seeds of pioneer species (e.g., Euphorbiaceae: Macaranga lowii, Mallotus spp; Ulmaceae: $G i$ ronniera nervosa; and Dilleniaceae: Dillenia excelsa and Tetracera akara). Psittacines, Green-winged Pigeons, and Crested Wood Partridges in the forest were observed to feed on Macaranga spp., Gironniera spp., and Chaetocarpus castinopsis (Euphorbiaceae) as well. Preference for Dilleniaceae and Euphorbiaceae over dipterocarps could not be established in feeding trials because of the difficulty in obtaining sufficient ripe seed. These non-dipterocarp species often reproduce during regional mast events involving the Dipterocarpaceae.
Social organization and foraging behavior of seed predators. - The nomadic seed-eating vertebrates are distinctive in that all possess relatively fluid or dynamic social structure. Long-tailed Parakeets are central-place foragers that are able to monitor their patchy resources in space and time. Group sizes ranged from solitary "scouts" to flocks of 200-300 birds in a Shorea crown. They actively recruited individuals by vocalizing and circling fruiting crowns many times before descending en masse to feed. Groups fed together in one area of the crown and coordinated movement within the crown. Continual adjustments in feeding group size appeared to reflect changes in patch size. During the minor mast, large groups were first seen during the initial day of crop attack, but as patches were depleted, flocks consisted of only a few birds (range: 8-200 birds in a crown).

The largest parakeet flocks fed in the late evenings, traveling up the river system to large, conspicuous trees near the river banks. The average time the birds spent feeding in the morning was significantly lower than the mean feeding times for flocks in the late afternoon (morning, $276.5 \pm 86.1$ min (mean $\pm 1 \mathrm{sE}$ ); afternoon, $1080 \pm 203.5 \mathrm{~min} ; P=0.028$; two-tailed $t$ test). During the morning, the parakeets fed in smaller groups on inland dispersed patches (flock size $37.2 \pm 4.8$ birds). Late evening foraging bouts showed more cohesion and large group size (foraging flock size 140.0 \pm 24.5 birds), presumably because flocks coordinated their travel to the roost site. In the evenings, they departed in one group (200-300 birds) to join other similar-sized subgroups feeding in several other valley systems. Their communal roost of $\sim 3000$ birds was located along the Nipa palm-lined banks in a coastal mangrove forest (Fig. 1).

Similarly, bearded pigs usually ranged as solitary individuals. However, during the mast, sows traveled together with 3-12 piglets and associated boars. Under dipterocarp crowns, up to five adults foraged together in loose assemblages. In both major mast events, pigs traveled into the study area in mixed groups of up to 70 individuals. During their long-distance migrations, hundreds to thousands of pigs travel together in unorganized, temporary, and fluid groups (Caldecott and Caldecott 1985). Assemblages may form during longdistance movement, but these may fission depending on the distribution of food resources. Only solitary adults are sighted during the intermast interval.

The Crested Wood Partridge exhibited a social structure similar to that of the bearded pig. When the Shorea lamellata trees began producing seed in 1986, solitary pairs fed below crowns. Multiple female and male groups were observed with chicks during the 1986 minor mast and in 1991. Two large groups exceeding 28 birds each were observed emigrating from the research area following the depletion of dipterocarp seed in the 1986 minor mast.

Vertebrate reproduction during mast-fruiting events.- 

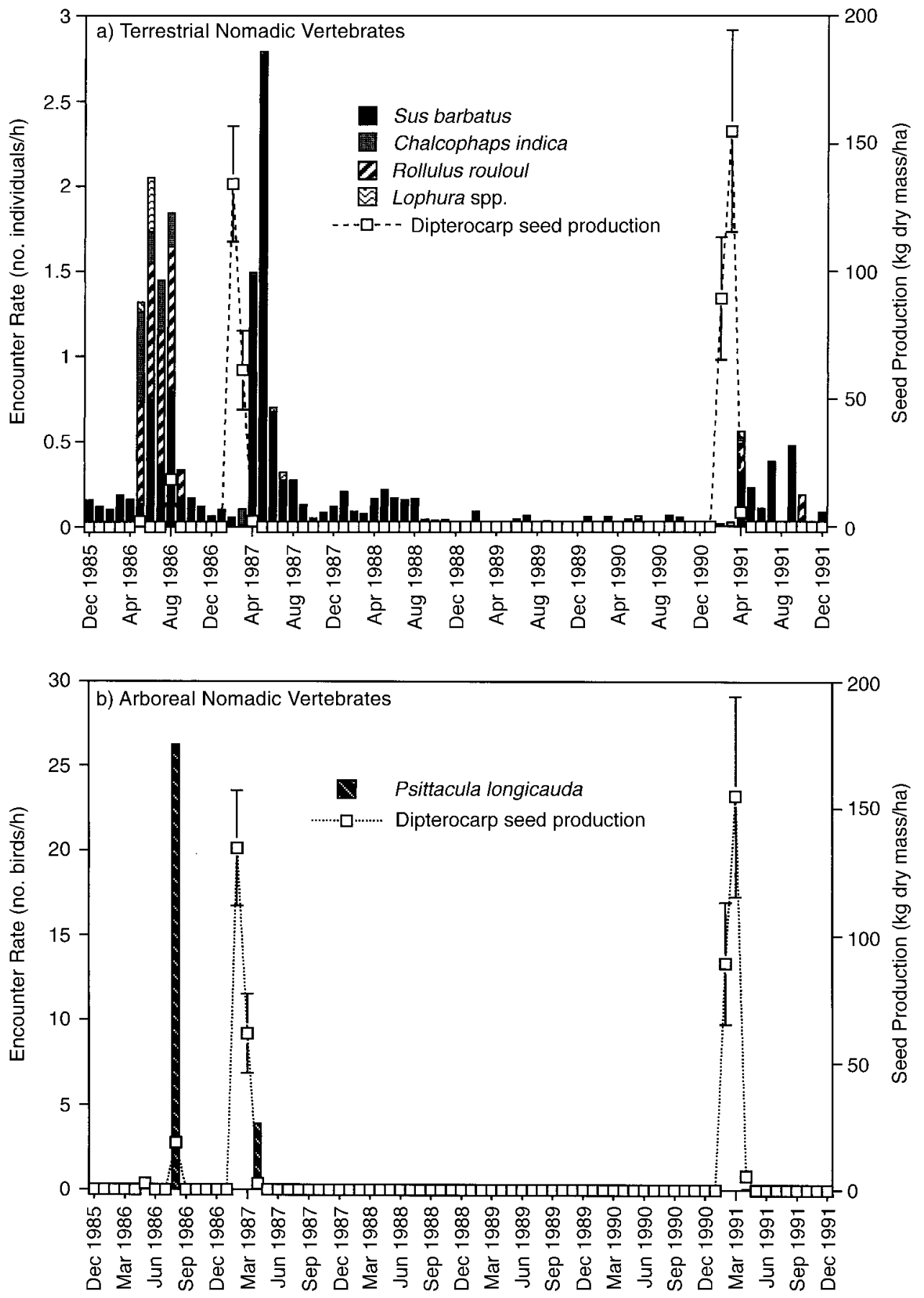

FIG. 8. Numerical response (mean $\pm 1 \mathrm{SE}$ ) of five nomadic vertebrates to the availability of dipterocarp seedfall from December 1985 to January 1992. Only lowland forest census routes were included (alluvial forest to lowland granite, 15-600 m a.s.1.). The sample includes a total of 10372 observation hours for (a) terrestrial nomadic vertebrates, and (b) arboreal nomadic vertebrates. Although bearded pigs were sighted throughout the sampling period at low levels, this is because a few individuals were concentrated primarily in the swamp forest and alluvial riverbanks, and not throughout the lowland forest. Seed production in 1987 and 1991 was calculated as the density of viable seed per month in 24 fruit-fall traps (each $3.06 \mathrm{~m}^{2}$ ), with a total collecting surface of 73.44 $\mathrm{m}^{2}$. Traps were collected weekly in 1991 and every two weeks in 1987. Seed production in 1986 was assessed by $1-\mathrm{m}^{2}$ ground plots across transects. 
From March 1985 to January 1993, young juvenile pigs were observed in the research area only during the two major dipterocarp mast events. On all other occasions, we observed only solitary adults or subadults. Litter size varied considerably (range 2-12 piglets). Rutting behavior was observed at the onset of dipterocarp flowering in both 1986 and 1987 (Fig. 9). Pairs of adult pigs were sighted at this time in the peat swamp forest and pig "nests" were found. Offspring arrived $\sim 210$ $220 \mathrm{~d}$ from the first observed rutting. Young piglets have a distinctive, striped natal coat. Only a few litters were recorded with a natal coat; thus, observed juveniles were 3-4 mo old, assessed by their lack of infant pelage and $20-30 \mathrm{~kg}$ size. Two pairs of Crested Fireback Pheasant (Lophura ignata) were observed to nest during the major masts of 1987 and 1991, whereas another pair was suspected of nesting during the minor mast of 1986. Although young chicks were not observed, eggshell remains were found at the onset of seedfall in major masts. Crested firebacks on a nest with eight eggs were sighted in primary forest in northeast Borneo only during the 1987-1998 dipterocarp fruiting (F. Lambert, personal communication). As dipterocarp seed availability increased in the minor mast, multiple male and female Crested Wood Partridge groups became abundant and most groups had numerous chicks. No chicks or juveniles were observed independent of adults. Reproductive adults or young juveniles of pigs, partridges, and jungle fowl were not observed outside the major mast events.

Intermast interval: alternate food sources and/or habitats.-After the minor mast, Sus barbatus was not observed regularly in the $15-\mathrm{km}^{2}$ study area for $7 \mathrm{mo}$ (October 1986-March 1987) until the next mast-fruiting event in April 1987. In the intermast intervals, 1985-1996 and 1988-1990, individual bearded pigs were observed in the lowlands whenever an oak (e.g., Lithocarpus echinifer or Quercus elmerri) or other species with ripe fruit was available. One or two pigs often remain as "residents" near riverbanks in alluvial and swamp forests (Caldecott 1986; Fig. 8).

During both major masts in 1987 and 1991, pigs returned to the lowlands on 6 April and 9 April, respectively. Bearded pigs were rarely observed in the lowlands from mid-December until early April in the 1991 mast (Fig. 8). Surveys of nearby lowland valleys in mid-February 1991 revealed that both pigs and jungle fowl were destroying dipterocarp seeds in these regions. Sightings of migrating pigs in both the montane regions (Mt. Palung and Mt. Ponti) and peat swamp forests reveal that multiple independent groups moved into the research area over both montane and peat swamp routes (Fig. 9). On 15 July 1991, 8-10 wk after dipterocarp seedfall, bearded pigs departed from the research area; frequent sightings did not occur until several months later. The movement patterns of bearded pigs appear chaotic, but not enough is known about the region to determine where they forage during the intermast interval.

In early 1990, numerous emaciated pigs ranged throughout the study area and many became destructive pests of the research camp. Moreover, L. M. Curran witnessed numerous battles over food sources, and adults had tusk-shaped scars and slashes. Most importantly, many large adult boars starved during the end of this period ( $3 \mathrm{yr}$ after the $1987 \mathrm{mast}$ ). At least six large, adult pigs $\left(\sim 0.4\right.$ individuals $\left./ \mathrm{km}^{2}\right)$ were found dead at the site. From these observations, the length of the masting cycle seems sufficient to depress populations in one of the longest lived dipterocarp seed predators, the bearded pig.

\section{Effects of seed predators on asynchronous species' population structure}

A common lowland dipterocarp species, Shorea lamellata, was asynchronous with the regional mast. Insect and vertebrate seed predators destroyed all seeds of this species (recorded in our plots across the forest and within the extensively sampled sandstone habitat) produced in the last decade, and perhaps for much longer. Shorea lamellata frequency distributions exhibited marked declines in subadult (29-59 cm dbh) trees (Fig. 10). At least $50 \%$ of the population is composed of extremely large adults $(>100 \mathrm{~cm}$ dbh). Despite a considerable basal area of reproductive adults $\left(1.1 \mathrm{~m}^{2} / \mathrm{ha}\right)$, saplings and small trees ( $1 \mathrm{~m}$ tall to $29 \mathrm{~cm} \mathrm{dbh}$ ) were not found within a set of 13 plots (1.3 ha) sampled across large forest areas. Subadults (10-29 cm dbh) were not found in supplementary transects samples (6.9 ha). For demographic comparison, Shorea hopeifolia, another common lowland, but mast-fruiting, species in the same survey area and on the same transects is wellstocked in juvenile and subadult size classes (Fig. 10). In addition, $S$. lamellata differs in demography from S. gratissima (sect. Anthoshorea), a species that shares invertebrate and vertebrate seed predators with $S$. $l a-$ mellata (sect. Anthoshorea) (Fig. 10). Seedling regeneration of the two common lowland Shorea species differs significantly. S. hopeifolia is the second most common Shorea species in lowland sandstone forest, whereas S. lamellata ranks third out of 17 species. Although $S$. hopeifolia density and adult basal area is $73.4 \%$ greater by area than that of S. lamellata, the species comparison of reproductive output is predicted to be similar because $S$. hopeifolia seeds are $61.1 \%$ larger than those of S. lamellata. In 1991, S. hopeifolia established $51800 \pm 25100$ seedlings/ha (mean \pm 1

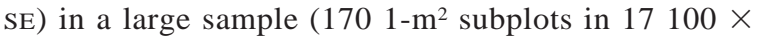
$30 \mathrm{~m}$ plots) across a $3-\mathrm{km}^{2}$ area (Table 2). Shorea lamellata seedlings were not found within these plots for either mast event.

\section{Discussion}

\section{Qualitative hypotheses to assess mast fruiting}

Janzen's (1974) predator satiation hypothesis for the evolution and maintenance of mast-fruiting in Bornean 


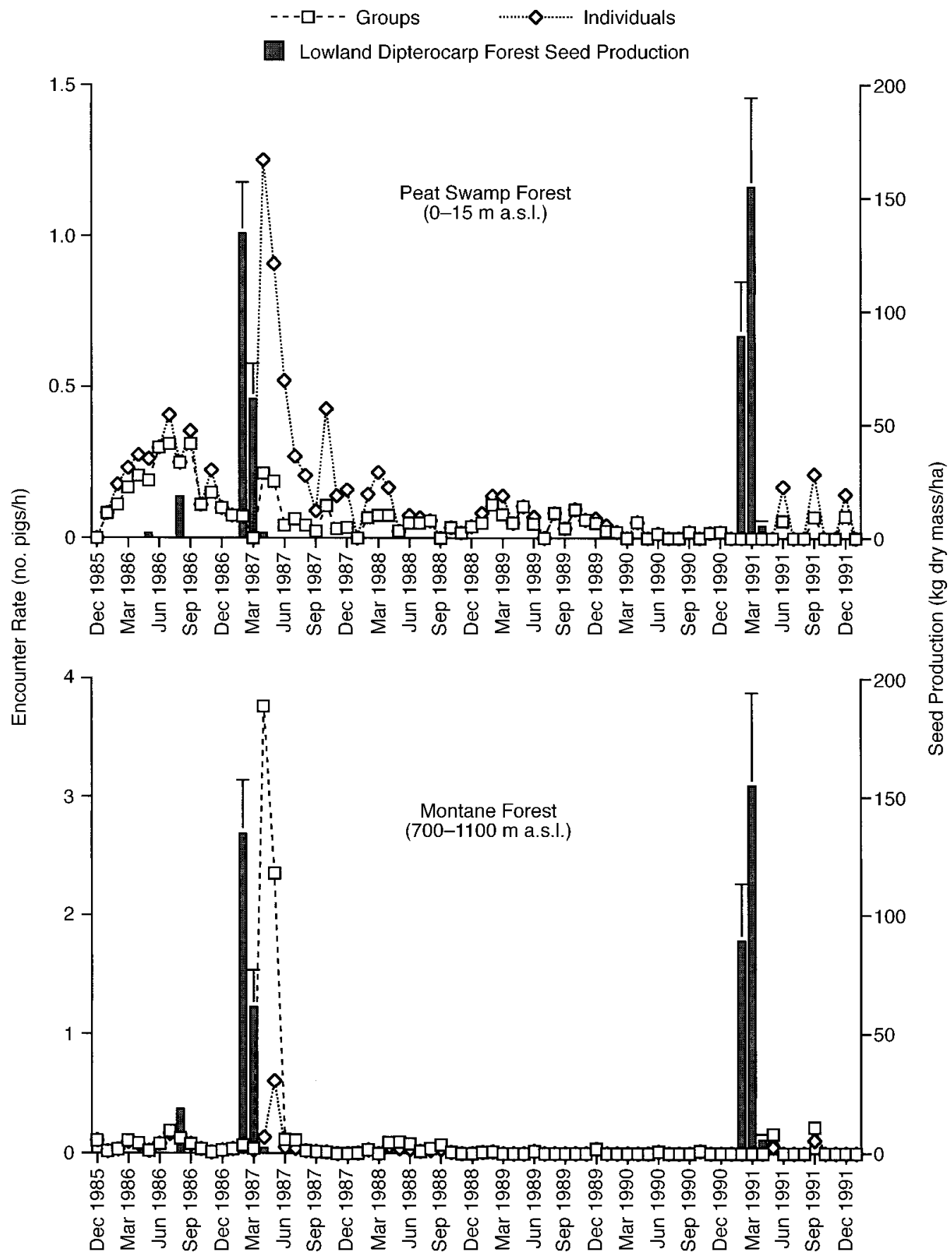

FIG. 9. Bearded pig movements (assessed by number encountered per hour) across peat swamp (top panel) and montane (bottom panel) forest formations in relation to dipterocarp seed production from 1986 to 1992 . There were $3305 \mathrm{~h}$ of observations in the peat swamp forest and $4593 \mathrm{~h}$ of vertebrate censuses in the montane forest.

Dipterocarpaceae contained four qualitative assertions. These are difficult to quantify or to assess statistically, because the specific ecological parameters must be defined independently for each mast-fruiting community. These are:

Generalized seed predators exist in Malesian rain forests.-At least 16 vertebrate seed predators were identified that displayed generalized seed consumption patterns across many dipterocarp species from several genera. Vertebrates discriminated little among dipterocarp species, and nomadic vertebrates showed no preference for different dipterocarp species.

Seed predator foraging behavior potentially has selective force to favor an extreme phenological pattern 


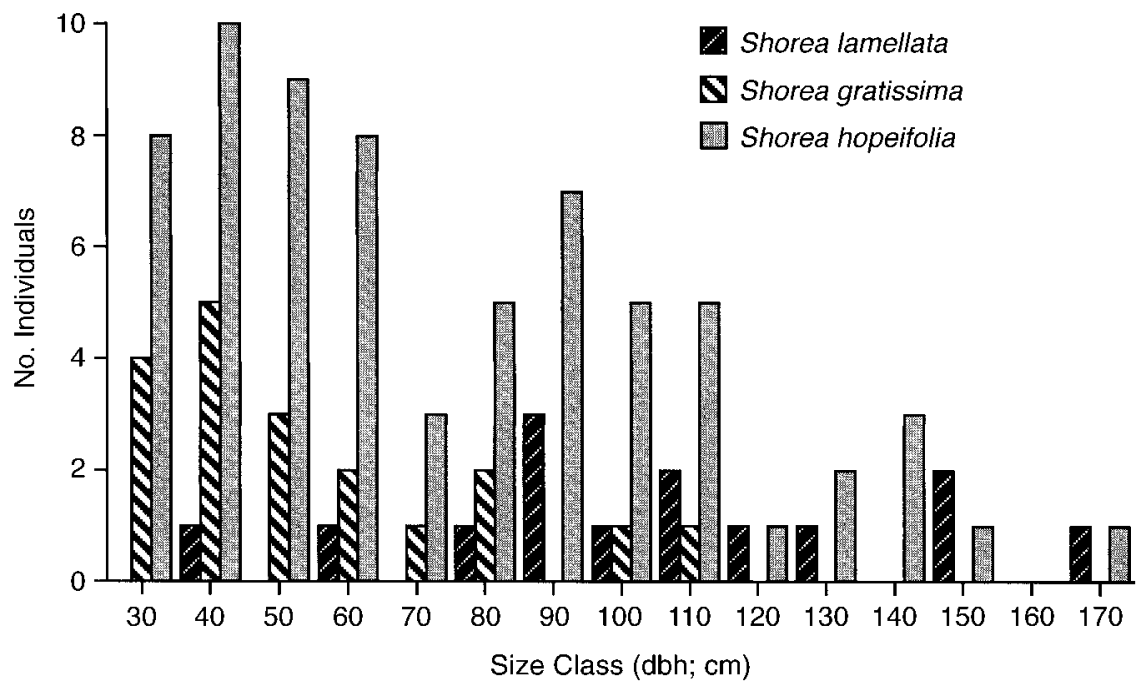

FIG. 10. Population structure, by dbh class, of the asynchronous Shorea lamellata (sect. Anthoshorea) in comparison with the sympatric, mast-fruiting S. hopeifolia (sect. Richetioides). The sampled forest is 6.9 ha for both species. A closely related congener, S. gratissima (Anthoshorea), sampled in the lowland granite forest, is also shown for comparison with S. lamellata.

over alternative reproductive strategies exhibiting fewer opportunity costs.-(Waller 1979, Silvertown 1980). These alternatives include fruiting more frequently (e.g., annually or once every $2-3 \mathrm{yr}$ ), with most populations still synchronized, or masting, but with sets of species out of phase with one another. In 1986, all monitored reproductive trees $(n=342)$ throughout the $15-\mathrm{km}^{2}$ area were attacked by a variety of seed-eating invertebrates and vertebrates. Even with an extensive search, we could not locate dipterocarp trees with seedlings surviving 1 mo post-seedfall. From observations of forest variation in seed production, a few dipterocarp trees, a common dipterocarp population, or a large percentage of individuals from 21 species within the dipterocarp community could not produce enough seed to escape vertebrate seed predators. Nomadic vertebrates easily destroyed all seed produced in synchrony by this suite of dipterocarp species in the 1986 mast. This destruction represented $86 \%$ of the adult populations of seven common species, or $>30 \%$ of the adult lowland basal area.
Superabundant seed is available to vertebrate predators only for a brief period.-From March 1985 until January 1993, viable dipterocarp seed was available throughout a large forest region on only two occasions: February to mid-April in 1987 and again in 1991. Furthermore, $\geq 94 \%$ of viable seed fell in just $11 \mathrm{wk}$, and on the whole, ripe dipterocarp seed was present in only 15-24 wk or 6\%, of this 380-wk period. This represents fruit fall of 49 sympatric species rather than a single species. With the exception of semelparous bamboo (Janzen 1976, Kelly 1994) and the semelparous Tachigalia versicolor (Foster 1977), we are aware of no iteroparous species with such limited, concentrated periods of seed availability (strict masting) as is found in this entire dipterocarp community. However, the Dipterocarpaceae are assumed to be a monophyletic group.

Although seed predator populations may explode during or immediately following mast episodes, they cannot sustain themselves in absence of the mast source.-In this study, seed availability was brief rel-

TABle 2. Population structure of two common lowland Shorea. All densities are presented as mean \pm 1 SE.

\begin{tabular}{|c|c|c|c|c|c|c|c|c|}
\hline \multirow[b]{2}{*}{ Species } & \multirow[b]{2}{*}{ Rank $\dagger$} & \multirow{2}{*}{$\begin{array}{c}\text { Adult } \\
\text { density } \\
\text { (no. } \\
\text { trees/ha) } \ddagger\end{array}$} & \multirow{2}{*}{$\begin{array}{c}\text { Basal } \\
\text { area } \\
\left(\mathrm{m}^{2} / \mathrm{ha}\right)\end{array}$} & \multirow{2}{*}{$\begin{array}{l}\text { Seed } \\
\text { size } \\
\text { (g dry } \\
\text { mass) }\end{array}$} & \multicolumn{2}{|c|}{$\begin{array}{l}\text { Viable dispersed seed } \\
\text { (no. seeds/ha) } \$\end{array}$} & \multicolumn{2}{|c|}{ Seedling density\| } \\
\hline & & & & & 1987 & 1991 & 1987 & 1991 \\
\hline $\begin{array}{l}\text { Shorea } \\
\text { lamellata } \\
\text { Shorea }\end{array}$ & 3 & $0.87 \pm 0.38$ & $1.06 \pm 0.26$ & 0.28 & 0 & 0 & 0 & 0 \\
\hline hopeifolia & 2 & $2.32 \pm 0.64$ & $1.62 \pm 0.66$ & 0.72 & $64700 \pm 23800$ & $122700 \pm 53500$ & $6470 \pm 3150$ & $51800 \pm 25100$ \\
\hline
\end{tabular}

† Abundance rank was determined by total basal area of Shorea spp. in the sandstone forest sample.

\$ Adult density is based on 23 transects $(6.9 \mathrm{ha})$ randomly stratified throughout a $3-\mathrm{km}^{2}$ sandstone forest.

$\S$ Viable dispersed seed was calculated from seed-trap samples throughout the lowland forests (48 traps, $149.9-\mathrm{m}^{2}$ collecting area).

\| Seedling densities were measured in $101-\mathrm{m}^{2}$ subplots for each of 17 transects (total $1701-\mathrm{m}^{2}$ subplots). The census was in May 1991, so that data for 1987 seedlings represent 4-yr-old survivors from the 1987 mast event. 
ative to both invertebrate and vertebrate seed predator reproductive cycles. Offspring of Bornean nomadic vertebrates such as bearded pigs were observed traveling with adults only just prior to the completion of dipterocarp seedfall in major mast years. Mean gestation time for Sus scrofa in northern latitudes is 114 d (Kilte 1988). Wild pigs have been reported to be sexually mature at 8-18 mo (Janzen 1974). Therefore, juveniles are unable to reach maturity and breed within a single mast event. Juveniles have not been observed to travel or forage independently of adults when dipterocarp seed is available. In the present study, the dipterocarp fruit fall period was sufficiently brief to prevent re-infestation, not only from pre-dispersal weevil larvae (which emerged as adults after dipterocarp seed was unavailable), but also from vertebrate offspring (which could not reach maturity during a mast event).

1. Population recruitment.-From March 1985 to January 1993, nomadic vertebrates (pigs, partridges, and jungle fowl) appeared to breed only during dipterocarp mast events. Rather than storing body fat during mast events and then mating, bearded pigs anticipate seed production and mate during flowering, well before peak seedfall (Caldecott and Caldecott 1985, Pfeffer and Caldecott 1986). Immature green cones of Piñon pine in North America are also correlated with breeding in Piñon Jays (Ligon 1974). These vertebrates use proximate cues to predict future seed production.

In the minor, or regionally asynchronous, mast event of this study, relative vertebrate densities in the lowlands increased $\geq 10$-fold for bearded pigs and $>100$ fold for Long-tailed Parakeets. Regional movements occurred over at least tens and probably hundreds of kilometers. It appears, then, that these vertebrates are able to respond to mast-fruiting events with large-scale movements and population immigration to a region with available dipterocarp seed. The late arrival of nomadic vertebrates during the 1987 mast was unexpected and was thought to be anomalous. However, the similar pattern observed in 1991 and other reports from Sarawak (Caldecott and Caldecott 1985) suggest that this pattern reflects the scattering of individuals during the intermast interval to search for food and the location of birth sites when the next mast occurs. It is not clear why parakeets did not arrive in the study area earlier in either the 1987 or the 1991 mast season. Also unexplained is the paucity of partridge and jungle fowl sightings in either major mast event.

Migratory vertebrates eating temperate and boreal mast seed show a similar pattern of pulsed population recruitment. In boreal and temperate seed-eating bird and rodent populations, eruptions and migrations were observed in years or seasons not prior to, but following, high mast seed production (Svärdson 1957, Perrins 1966, Newton 1972, Bock and Lepthien 1976, Ligon 1978, Jensen 1982, Wolff 1996). These vertebrates may breed before, during, or after large seed crops are pro- duced, but major population recruitment events and/or movements are recorded following the seed production. Censuses of Bornean bearded pig (mating prior to a mast), jungle fowl, and partridges (reproducing during a mast), along with mark-and-recapture studies of four spiny rat (Maxomys spp.) populations (reproducing after peak mast) exhibit major population increases following peak seed production (Curran 1994).

2. Intermast interval.-Because Bornean dipterocarp reproduction is correlated with climatic changes associated with the El Niño-Southern Oscillation, the intermast interval is irregular and fruiting occurs at least once every 2-7 yr (Rasmusson 1985, Leighton and Wirawan 1986, Ashton et al. 1988, Salafsky 1994, Trenberth and Hoar 1996, Trenberth 1997). In this study, a minor event was triggered by a weak cue (1986) preceding a major ENSO event (1987). From West Kalimantan illipe nut export figures, "good" years occur, on average, every four years. Seed-eating vertebrates experience an irregular intermast interval averaging four years in duration and they must survive this relatively long period between successive dipterocarp seed production. The nomadic vertebrates switch habitats and move considerable distances. One report provides anecdotal evidence for the tremendous distance covered by an individual pig. A bearded pig struck with a distinctive spear near Long Lellang, Sarawak was killed a few days later $>50 \mathrm{~km}$ from this spot with the spear still lodged in its side (J. Caldecott, personal communication). Nomadic vertebrates, especially pigs, partridges, and jungle fowl, often travel interspecifically. The movement patterns of nomadic vertebrates during the intermast interval, and their alternate food sources, remain largely unknown. Common wisdom from local peoples, naturalists, and anthropologists working with wild boar hunters suggests that montane oak forests with acorns influence large population movement of bearded pigs (Banks 1931, Anonymous 1953, Caldecott and Caldecott 1985, Caldecott 1986, Pfeffer and Caldecott 1986, Caldecott et al. 1993)

Pigs survive intermast intervals by feeding on a diversity of asynchronously fruiting species (e.g., Lithocarpus spp. and Quercus spp. in the montane zone, and Tetramerista glabra and Palaquium leiocarpum in the peat swamp) and by scavenging the forest floor (e.g., palm meristems, earthworms). Although normally they are extremely wary of humans, bearded pigs that are desperate for food are bold and raid agricultural areas (Dove 1993). In the research area, bearded pigs invaded the compound (even buildings) in search of food, and by doing so, they increased their vulnerability to human predation. For bearded pigs, the length of intermast interval prevents many juveniles from reaching maturity and perhaps some from breeding at the next flowering event. From our observations of adult pig starvation and mortality late in the intermast interval, the length of the masting cycle seems sufficient 
to depress populations in the bearded pig, one of the longest lived dipterocarp seed predators.

\section{Predator satiation hypothesis: correct predictions, incorrect mechanisms}

Vertebrate seed predators do not destroy seeds throughout fruit fall, as found for resident vertebrates feeding on periodic cycadas and mayflies (Karban 1982, Sweeney and Vannote 1982, Williams et al. 1993). Rather, dipterocarps escape predation because they are not preferred by resident seed predators over other locally available food sources. These preferences differ for each potential seed predator. Over larger scales, dipterocarp seeds escape predation by community phenological synchrony and long intermast intervals that disrupt and depress nomadic predator populations. Thus, the mechanisms that result in seed escape in Bornean dipterocarps have been found to differ from those predicted to occur in mast-fruiting populations. Two new hypotheses that distinguish between resident and nomadic vertebrate seed escape are required.

\section{"Interfamilial satiation": resident vertebrate feeding preferences for non-dipterocarp food sources}

Community reproduction of all species (not just dipterocarps) is an essential component of "interfamilial satiation" similar to "apparent competition" (sensu Holt 1984, Holt and Lawton 1994). For resident seed predators, interfamilial satiation states that seed availability across plant families affects vertebrate foraging preferences and, as a result, the prospects for dipterocarp seed maturation. In these forests, dipterocarps are the most common canopy and emergent trees (Fig. 2; $32-80 \%$ of basal area $>49 \mathrm{~cm} \mathrm{dbh}$, except in peat swamp forest). During mast events, dipterocarps dominate species abundance on a number of scales: crop or patch size, patch density, and dispersion, as well as basal area or density of reproductive trees. However, many non-dipterocarp species reproduce during dipterocarp mast-fruiting events; some fruit annually, irregularly, or supra-annually (Medway 1972, Leighton and Leighton 1983, Appanah 1985, Curran 1994). Therefore, field observations of feeding on non-dipterocarp fruit sources appear to reflect choice or feeding selectivity, as would be assessed by a number of preference indices (Cock 1978). Although residents have the potential to destroy large quantities of seed, they apparently prefer to eat other available non-dipterocarp species. During the 1987 major mast at the GP research site, Salafsky (1988) conducted an in-depth study of red leaf monkey foraging ecology (439 feeding observations). Using detailed feeding observations of a focal Presbytis rubicunda group, in relation to patch size, fruit nutritional content, and species' densities in the monkey's diet, he found that dipterocarp seeds in this major mast event ranked very low in preference by these large-bodied resident granivores. Many other non-dipterocarp resources were also available. If preferred non-dipterocarp food sources are less available (as in the tail of the 1987 major mast), seeds of Dipterocarpus spp. may be relatively common in their diet. Similarly, orangutans (Pongo pygmaeus) generally ignored dipterocarp seed during the peak fruit fall in the major mast events of 1987 and 1991, and fed on other available food resources. In a similar minor mast event, when preferred non-dipterocarp food sources were less available, seeds of a dipterocarp species ranked in the top 10 species in the diet of orangutans (Leighton 1993).

Observations of preference rankings have been shown to affect seed escape and, thus, seedling establishment in temperate mast-fruiting communities. When Quercus populations have large crops, European jays ignore the beech crop and disperse many acorns. When the beech fruited in 1972-1973 and again in 1983, no acorns were produced and the jays concentrated their caching efforts on beech (Nilsson 1985). Jays strongly prefer acorns to beech mast (Bossema 1979). North American Wild Turkeys (Meleagris gallopavo) and Bobwhite Quail (Colinus virginianus) also display similar preferences for acorns over beech (Stoddard 1931, Williams 1981), whereas Passenger Pigeons may have selected beech seed over acorns (Mitchell 1935, Schorger 1955). Rodent seed predators in oak-beech forest will prey on seeds of all available mast-fruiting species, but species-specific preferences have been observed (Jensen 1982, 1985). White-tailed deer (Odocoileus virginianus) do not display preferences among three sympatric oak species, but avoid hickory species (McShea and Schwede 1993). In both temperate and Bornean forests, a diversity of sympatric vertebrates with a suite of shifting and overlapping feeding preferences could influence the probability of seed escape. Yet, dipterocarp seeds offer a protein- and lipid-rich food source in large patches. For some unknown reason, resident vertebrates in Borneo rarely feed on this abundant, high-nutrient resource, whereas most temperate vertebrate species appear to feed on the most abundant seeds when available. To test interfamilial satiation, detailed studies on feeding preferences of each vertebrate predator are required to determine the relative ranking of dipterocarps within these agents' diets, and to document food webs of generalist (polyphagous) seed predators. These preferences are expected to change with the relative availability and reproductive response of non-dipterocarp food sources.

\section{"Regional escape": distribution of nomadic vertebrates with synchronous seedfall}

For nomadic vertebrates, dipterocarp seed escape occurs in the context of a markedly uniform regional seedfall synchrony, both in time and space, contrasted by patchy vertebrate distributions. In both major mast events of this study, nomadic seed predators did not arrive at GP until most of the dipterocarp seed had 
already been dispersed. Although the predator satiation hypothesis predicts disproportionate seed predation on the tails of the fruit fall distribution, it does not predict absolute seed escape during peak seedfall, or the absence of vertebrate seed predators from a region. Medway (1972) also documented two similar, major, community-wide mast events in 1964 and 1969, when nomadic vertebrates were absent from his study area. With four documented cases of nearly absolute seed escape during major mast events, this pattern appears to require a revision of hypotheses to incorporate a broader spatial scale or hierarchial level, such as a behavioral ecology of ecological landscapes (Lima and Zollner 1996). Nomadic vertebrates must eat dipterocarp seed somewhere in the region during the peak of the mast. Rather than local, short-term satiation of predators accounting for survivorship of locally available seed, "regional escape" predicts that a local forest community either will escape seed destruction completely or will incur substantial seed losses as a result of the limits on broader regional distribution of nomadic vertebrates. To test this hypothesis, one must document the distribution of pigs across the landscape, coupled with the spatial scale of fruiting and with pig foraging behavior, including patch choice and decision rules about ranging. This hypothesis holds that a predator has no long-term preferences for a particular region. It also predicts that, although seed production levels may be uniformly high, survivorship is not uniform across a landscape.

\section{Role of vertebrates in the evolution of mast fruiting}

Reviews on the evolution of masting assume that a rare mast-fruiting species invades or develops within a community of asynchronous populations or individuals (Ims 1990, Lalonde and Roitberg 1992, Waller 1993). Ims (1990) states that one of the hidden predictions of Darling's (1938) predator-swamping hypothesis was that predators are specialists exhibiting a Hollings' Type II functional response curve. Ims' (1990) analyses show that reproductive synchrony as a predator-swamping strategy has an adaptive value only when the prey is exposed to a specialist predator, but not when the predator displays a generalist type of functional response. Lalonde and Roitberg (1992) also found that when high search efficiencies are coupled with short handling times, seed parasites are so good at finding seeds that masting would be an ineffective strategy for seed escape. For a masting strategy to be favored, specialist predators must be inefficient at locating patches, display long handling times, and/or show rapid satiation.

Predictions of these models are not supported by observations of dipterocarp seed predators in West Kalimantan. Over vast areas and within a brief two weeks, generalized dipterocarp seed predators located and destroyed large seed crops from at least nine mast-fruiting populations. Most importantly, their behavior dis- played a type III or IV response, rather, than a functional type II response (Ims 1990). The spatial scale of functional responses must be considered (Wiens 1989, Hanski 1991, Lima and Zollner 1996). Observations presented here support Janzen's $(1974,1976)$ predictions for fluid foraging behavior and dynamic social structure (Collias et al. 1966, Collias and Collias 1967) of seed-eating vertebrates associated with semelparous bamboo and mast-fruiting dipterocarps. Moreover, similar seed predator guilds exist in both forest communities. Jungle fowl, pigs, Green-winged Pigeon, and other seed predators such as rodents and humans purported to feed on semelparous nilou (Strobilanthus) in South Asia (Janzen 1976) also feed on dipterocarps in Southeast Asian forests. These observations contradict the basic conditions proposed in order for mast fruiting in a rare population to have a selective advantage (Waller 1993).

\section{Distributions of vertebrate seed predators with interspecific mast-fruiting Dipterocarpaceae}

Over 385 dipterocarp species from nine genera may participate in supra-annual, synchronous reproduction across forests in Peninsular Malaysia, Sumatra, and Borneo, a $\sim 1.35 \times 10^{6} \mathrm{~km}^{2}$ mast-fruiting biogeographical area (Wood 1956). Notably, species distributions of the Crested Wood Partridge (Rollulus rouloul), the Long-tailed Parakeet (Psittacula longicauda), the BlueRumped Parrot (Psittinus cyanurus), and both jungle fowl species (Lophura ignata and L. erythrophthalma) correspond exactly with the region of interspecific mast-fruiting dipterocarps. (Smythies 1960, Johnsgard 1988, Forshaw 1989). The Green-winged Pigeon (Chalcophaps indica) is widespread throughout South and Southeast Asia (Goodwin 1977). The bearded pig (Sus barbatus barbatus) is found on the island of Borneo, with subspecies in Peninsular Malaysia, Sumatra, and the Philippines (Groves 1981). The indigenous common wild pig (Sus scrofa), however, replaces the bearded pig on Sumatra and Peninsular Malaysia (Groves 1981).

\section{Foreboding similarities with temperate vertebrate seed predators: conservation implications}

The Passenger Pigeon (Ectopistes migratorius) numbered over three billion birds when Europeans arrived on North American shores, and contributed 25-40\% of the biomass of the entire avian community of North America (Schorger 1955). Passenger Pigeons fed as generalized seed predators on a variety of seeds produced by mast-fruiting trees: 13 species of Quercus, Fagus grandifolia, and Castanea dentata, as well as Pinus spp., Tsuga canadensis, and Ulmus spp. (Mitchell 1935, Schorger 1955). The destruction of beech and oak forests, primarily due to land clearing, was a major factor in the precipitous decline of Passenger Pigeons, in that these central-place foragers nested colonially and their reproduction was tied to sufficient mast from 
the previous fall (Mitchell 1935, Schorger 1955). Without the critical level of fruit production and large numbers of birds to prevent excessive nest predation, reproduction failed. Over-hunting at colonial roosting sites (Mitchell 1935) decimated the few remaining flocks that were already reduced below critical densities for successful reproduction. By about 1890, only small, remnant flocks of a few hundred birds remained before their final extinction in 1900 (Schorger 1955).

The Carolina Parakeet (Psittacus carolinensis) was last seen in the wild in 1901. This parakeet foraged in large flocks, nested primarily in swamp forests, and relied on mast-fruiting North American canebrakes (Arundinaria gigantea), but shifted habitats to feed on seasonally available mast nuts such as beech and hickory (Fuller 1987, Forshaw 1989, Conover 1994). The European wild boar (Sus scrofa) fed on oak and beech mast and was renowned for its spectacular migrations before becoming locally extinct throughout most of Europe in the late 1600s (Mellen 1952). North American Wild Turkey (Meleagris gallopavo) and other terrestrial fowl that fed primarily on acorn and beech mast also were reduced to scattered and rare populations (Schorger 1966). Only intensive conservation, management, and re-introduction schemes have kept Wild Turkeys from extinction (Dickson 1992).

All mast-fruiting communities, both temperate and tropical, support nomadic vertebrates exhibiting fluid social organization, extensive ranges, and generalized seed predation on supra-anually fruiting resources. In most cases, their reproduction is linked to the availability of sufficient mast seed. Central-place foragers such as Passenger Pigeons and Carolina Parakeets may have been particularly adept at exploiting patchy resources in time and space, with colonial roosts serving as "information centers" (Ward and Zahavi 1972). Pigs (Sus scrofa and S. barbatus), parakeets and parrots (Psittacula longicauda and Psittius cyanurus), and jungle fowl (Lophura spp.) in Malesian tropics share these ecological characteristics with temperate counterparts.

\section{Significance of the natural "experiment"}

Fleming (1992:383) remarked that:

strong inferences about underlying causes and effects in biology usually require an experimental approach-an approach that is virtually impossible to pursue when dealing with highly mobile species of birds and mammals. [Tracking resource availability.]

Similarly, Crawley (1989:53) commented that it is:

impossible to do realistic field experiments on masting ... [because] to satiate predators over a meaningful area, the density of seed would need to be increased experimentally on plots of perhaps hundreds of hectares.

Climatic variation associated with the El NiñoSouthern Oscillation was the key to the natural "ex- periment" on vertebrate seed predation of mast-fruiting dipterocarp seeds. In this case, without the natural variation in fruit production provided by the minor mast, the role of nomadic vertebrates, especially Long-tailed Parakeets, in the selection for community-wide synchrony of dipterocarp fruit fall would have been overlooked or undetectable on small scales or with relatively brief studies. The majority of these nomadic vertebrates were observed in the lowland dipterocarp forest only during mast-fruiting events. Although other forest regions (i.e., swamp, mangrove, and montane forests) are essential to maintain populations during the intermast interval, the lowland dipterocarp forests may be critical to these vertebrates for reproduction and/or offspring survival. Most importantly, the foraging pattern observed during both major masts (i.e., nomadic vertebrates arriving late on the tails of dipterocarp fruit fall) is correlated with regional fruit fall synchrony. Resident and nomadic vertebrates appear to impart stablilizing selection for tight reproductive synchrony within dipterocarps. Early-fruiting species are subject to seed destruction by resident vertebrates if preferred foods are unavailable, whereas late-fruiting species cannot escape nomadic vertebrates, if present. In summary, both guilds of vertebrates may impart strong selective pressure for low variance in fruit fall times or interspecific synchrony.

Seed predators also create fluctuations in dipterocarp species' recruitment, thereby influencing population dynamics and community interactions. Because of the lack of interspecific synchrony and, as a result, failure to successfully regenerate from 1984 to 1993, Shorea lamellata may be marching to local extinction within the GP study area (but see Condit et al. 1998). This population shares both invertebrate and vertebrate seed predators with other mast-fruiting populations. Therefore, if they were to fruit synchronously with the community, S. lamellata individuals would be expected to reduce seed losses to these agents. The entire adult population, however, was consistently out of reproductive synchrony with the rest of the dipterocarp community. Conversely, this asynchronous reproduction by S. lamellata may be a strategy to avoid interspecific seedling competition. Shorea lamellata produces the smallest seeds of all sympatric Shorea species, and seed production occurred a few months before community events, when predator populations should be at their lowest densities. In most years, predators destroy $S$. lamellata seed, but occasional episodes may be successful (i.e., undetected by vertebrates), resulting in pulses of regeneration. In either case, a reproductive strategy or a miscue, insect, and vertebrate seed predators appear to have directly influenced plant population dynamics and forest composition.

\section{Importance of long-term field studies for investigating selective factors}

This investigation demonstrates the importance of long-term community studies for understanding mech- 
anisms affecting the evolution of plant reproductive strategies. The major selective events for both vertebrates and economically important timber trees occurred on temporal scales much longer than most research projects could measure. Grant and Grant (1993) documented the significance of perturbations associated with the El Niño-Southern Oscillation (ENSO) on selection influencing Darwin's finch communities on the Galapagos Islands. The major reproductive events of both dipterocarps and vertebrates in Bornean forest also occur primarily in ENSO years. In both Bornean and Galapagos investigations, an evaluation of the impact of ENSO was possible only with a baseline of research in non-ENSO years. Other long-term tropical studies (i.e., of large mammals and tree communities) indicate that ENSO events create major perturbations in population structure (Foster 1982, Condit et al. 1992, Wright et al. 1999). Thus, results from short-term investigations must be approached cautiously, as community interactions may be dictated by relatively rare, but major, events in the organism's lifetime.

Many researchers may be evaluating causal processes on inappropriate scales or within disrupted systems. For example, the relative importance of vertebrate predator satiation for reproductive synchrony within temperate mast-fruiting communities may be greatly underestimated at present, because the major seed predators have been at least locally exterminated (Nilsson 1985, Nilsson and Wästljung 1987, Norton and Kelly 1988, Sork et al. 1993). With the loss of their most significant seed predators over a century ago, oaks, beech, and podocarps may be experiencing "relaxed" selection or little negative impact for asynchronous reproduction. Observations of mast-fruiting communities in Sweden (from 1895 to 1955) indicate that Abies, Betula, Quercus, and Fagus crops were highly synchronized in multiyear intervals over large regions (Svärdson 1957, Bock and Lepthien 1976). Spruce trees in these regions presently reproduce on roughly annual cycles and at smaller tree sizes (P. Berthold, personal communication). Therefore, without vertebrate seed predators and altered edaphic conditions, reproductive synchrony may be disrupted, and the relative importance of insect seed predators or weather variables may be inflated. When one searches for the relative importance of factors influencing selection, climatic factors may appear to explain a large proportion of the presently observed variance, yet causal factors that shaped the evolution of many traits remain undetected.

\section{CONCLUSIONS}

This study demonstrates that the daily and seasonal movement patterns, local population fluctuations, the timing of breeding and intra- and interspecific social interactions of nomadic vertebrate seed predators in Bornean forests have been strongly influenced by dipterocarp seed availability and mast-fruiting cycles. Be- cause of the biomass, searching efficiency, and brief handling times of these highly mobile predators, dipterocarps must synchronize episodic reproduction both within communities and across vast forest regions to ensure seedling establishment. Apparently using climatic cues associated with the El Niño-Southern Oscillation, dipterocarps display episodic reproduction at $\sim 4$-yr intervals. As a result of long intermast intervals and brief dipterocarp fruit fall periods, predator populations may be depressed and cannot increase beyond a single breeding event during a mast episode. Therefore, intercommunity synchrony, brief seed availability, and long intermast intervals are a result of a reproductive strategy known as predator satiation. In years of heavy seed production, this reproductive strategy is effective, because it results in regional predator satiation and considerable seedling regeneration. Although the predator satiation hypothesis was supported by this study, the mechanisms affecting seed escape differed from expectations. Therefore, two new hypotheses were generated to account for observations of vertebrate foraging and ranging behavior: the "interfamilial satiation" and the "regional escape."

\section{ACKNOWLEDGMENTS}

We thank the Government of Indonesia for the privilege to conduct scientific research in West Kalimantan. Several institutes and individuals sponsored this project. We express our specific thanks to Dr. Soetikno Wirjoatmijo, Dr. Dedy Darnaedi, and Dr. Rochadi Abdulhadi, Indonesian Institute of Sciences, (LIPI-PPPB), Mr. Herman Prayitno, Indonesian Parks and Conservation (KSDA-Kalbar), the late Mr. Amir, Land Use Planning and Development, (BAPPEDA-Kalbar), and Dr. Kuswata Kartawinata (formerly UNESCO-MAB Indonesia). LMC received financial support from a NSF Predoctoral Fellowship, Wildlife Conservation International (now Society-WCS), W. Alton Jones Foundation, Conservation International (CI), Biodiversity Support Program (Grant Number 7510), UNESCO-MAB Young Scientist Training Program, University of Michigan, and Sigma Xi. M. Leighton received financial support for the Cabang Panti research site from NSF (BNS-840-9299), National Geographic Society, Conservation, Food and Health Foundation, and Merck. Several researchers contributed to this study: Abdullah, K. Ardlie, Priyo Budi Asmore, Tri Atmowidji, Bekti, L. Borkenhagen, Izefri Caniago, C. Cannon, Yeni Damayanti, C. Darling, Darmawan, E. Gillis, Hermanto, Ismail, Johannes, C. Knab, D. Lawrence, D. Lucas, N. MaKinuddin, J. Mitani, Morni, Muswar, K. Omland, P. Palmiotto, G. Paoli, Anjar Rafiastanto, N. Salafsky, Sumen, Adi Susilo, Sutrichno, Tadyn, Utai, C. Webb, and S. Zens. P. S. Ashton, Gray Herbarium, Harvard University, reviewed all dipterocarp specimens. C. H. Lyal, Museum of Natural History, London, provided species determinations of dipterocarp insect seed predator collections. M. E. Siddall offered his randomization computer programs for analyses and greatly improved the quality of this work. B. R. Grant, P. R. Grant, S. H. Hubbell, R. S. Ostfeld, D. Rubenstein, M. E. Siddall, and S. J. Wright, as well as an anonymous reviewer, provided constructive comments on earlier manuscript drafts. Special thanks to D. H. Janzen, whose analytical contributions provided the foundation for this work.

\section{Literature Cited}

Anonymous. 1953. Bearded pig swim again. Malayan Nature Journal 8:118-120. 
Appanah, S. 1985. General flowering in the climax rain forests of South-east Asia. Journal of Tropical Ecology 1:225240.

Appanah, S. 1990. Plant-pollinator interactions in Malaysian rain forests. Pages 85-101 in K. S. Bawa and M. Hadley, editors. Reproductive ecology of tropical forest plants. Man in the Biosphere Series. Volume 7. UNESCO-MAB, Paris, France.

Ashton, P. S. 1982. Dipterocarpaceae. Flora Malesiana Series 1: Spermatophyta (flowering plants) 9:251-552. Martinus Nijhoff, The Hague, the Netherlands.

Ashton, P. S., T. J. Givnish, and S. Appanah. 1988. Staggered flowering in the Dipterocarpaceae: new insights into floral induction and the evolution of mast fruiting in the aseasonal tropics. American Naturalist 132:44-66.

Augspurger, C. K. 1981. Reproductive synchrony of a tropical shrub: experimental studies on effects of pollinators and seed predators on Hybanthus prunifolius (Violaceae) Ecology 62:775-788.

Banks, E. 1931. A popular account of the mammals of Borneo. Journal of the Malay Branch of the Royal Asiatic Society 9:1-139.

Bock, C. E., and L. W. Lepthien. 1976. Synchronous eruptions of boreal seed-eating birds. American Naturalist 110: $559-571$

Bossema, I. 1979. Jays and oaks: an eco-ethological study of symbiosis. Behaviour 70:1-117.

Burgess, P. F. 1975. Silviculture in the hill forests of the Malay Peninsula. Forest Research Institute, Research Pamphlet Number 66. Kepong, Malaysia.

Caldecott, J. O. 1986. Hunting and wildlife management in Sarawak. World Wildlife Fund, Kuala Lumpur, Malaysia.

Caldecott, J. O., R. A. Blouch, and A. A. Macdonald. 1993 The bearded pig (Sus barbatus). Pages 136-144 in W. L. R. Oliver, editor. Pigs, peccaries, and hippos: status, survey, and Conservation Action Plan. IUCN/SSC. World Conservation Centre, Gland, Switzerland.

Caldecott, J. O., and S. Caldecott. 1985. A horde of pork. New Scientist 110:32-35.

Chan, H. T. 1977. Reproductive biology of some Malaysian dipterocarps. Dissertation. University of Aberdeen, Aberdeen, Scotland.

Chan, H. T. 1980. Reproductive biology of some Malaysian dipterocarps. II. Fruiting biology and seedling studies. Malaysian Forester 43:438-451.

Chan, H. T. 1981. Reproductive biology of some Malaysian dipterocarps. III. Breeding systems. Malaysian Forester 44 28-36.

Chan, H. T., and S. Appanah. 1980. Reproductive biology of some Malaysian dipterocarps. I. Flowering biology. Malaysian Forester 43:132-143.

Cock, M. J. W. 1978. The assessment of preference. Journal of Animal Ecology 47:805-816.

Collias, N. E., and E. C. Collias. 1967. A field study of the Red Jungle Fowl in north-central India. Condor 69:360386.

Collias, N. E., E. C. Collias, D. Hunsaker, and L. Minning. 1966. Locality fixation, mobility and social organization within an unconfined population of Red Jungle Fowl. Animal Behavior 14:550-559.

Condit, R., S. P. Hubbell, and R. B. Foster. 1992. Stability and change of a neotropical moist forest over a decade. BioScience 42:822-828.

Condit, R., R. Sukumar, S. P. Hubbell, and R. B. Foster. 1998. Predicting population trends from size distributions: a direct test in a tropical tree community. American Naturalist 152:495-509.

Conover, A. 1994. A new world comes to life, discovered in a stalk of bamboo. Smithsonian 25:121-128.
Crawley, M. J. 1983. Herbivory: the dynamics of animalplant interactions. Blackwell Scientific, Oxford, UK.

Crawley, M. J. 1989. The relative importance of vertebrate and invertebrate herbivores in plant population dynamics. Pages 45-71 in E. A. Bernays, editor. Insect-plant interactions. Volume I. CRC Press, Boca Raton, Florida, USA.

Crawley, M. J., and C. R. Long. 1995. Alternate bearing, predator-satiation and seedling recruitment in Quercus rob$u r$ L. Journal of Ecology 83:683-696.

Curran, L. M. 1994. The ecology and evolution of mastfruiting in Bornean Dipterocarpaceae: a general ectomycorrhizal theory. Dissertation. Princeton University, Princeton, New Jersey, USA.

Curran, L. M., and C. O. Webb. 2000. Experimental tests of the spatiotemporal scale of seed predation in mast-fruiting Dipterocarpaceae. Ecology 70:129-148.

Darling, F. F. 1938. Bird flocks and breeding cycle. Cambridge University Press, Cambridge, UK.

De Steven, D. 1982. Seed production and seed mortality in a temperate forest shrub (witch-hazel, Hamamelis virginiana). Journal of Ecology 70:437-443.

De Steven, D. 1983. Reproductive consequences of insect seed predation in Hammamelis virginiana. Ecology 64:8998.

De Steven, D., and F. E. Putz. 1984. Impact of mammals on early recruitment of a tropical canopy tree, Dipteryx panamensis, in Panama. Oikos 43:207-216.

Dickson, J. G. 1992. The Wild Turkey: biology and management. Stackpole Books. Harrisburg, Pennsylvania, USA.

Dove, M. R. 1993. The responses of Dyak and bearded pig to mast-fruiting in Kalimantan: an analysis of nature-culture analogies. Environmental Series Number 7, East-West Center Reprints, Honolulu, Hawaii, USA.

Fenner, M. 1985. Seed ecology. Chapman and Hall, London, UK.

Fleming, T. 1992. How do fruit- and nectar-feeding birds and mammals track their food resources? Pages 355-393 in M. D. Hunter, T. Ohgushi, and P. W. Price, editors. Effects of resource distribution on animal-plant interactions. Academic Press, New York, USA.

Forshaw, J. M. 1989. Parrots of the world. Third revised edition. Lansdowne, Melbourne, Australia.

Foster, R. B. 1977. Tachigalia versicolor is a suicidal neotropical tree. Nature 268:624-625.

Foster, R. B. 1982. Famine on Barro Colorado Island. Pages 201-212 in E. G. Leigh, Jr., A. S. Rand, and D. M. Windsor, editors. The ecology of a tropical forest: seasonal rhythms and long-term changes. Smithsonian Institution Press, Washington, D.C., USA.

Fuller, E. 1987. Extinct birds. Facts on File Publication, New York, New York, USA.

Gochfeld, M. 1982. Reproductive synchrony and predatorsatiation: an analogy between the Darling effect in birds and mast-fruiting plants. Auk 99:586-587.

Goodwin, D. 1977. Pigeons and doves of the world. Second edition. British Museum of Natural History, Comstock Publishing, Ithaca, New York, USA.

Gould, K., and M. Andau. 1989. Selection and rejection of five species of dipterocarp fruits by captive primates, squirrels, and hornbills. Malayan Nature Journal 42:245-249.

Grant, B. R., and P. R. Grant. 1993. Evolution of Darwin's finches caused by a rare climatic event. Proceedings of the Royal Society of London B 336:111-117.

Groves, C. 1981. Ancestors for the pigs: taxonomy and phylogeny of the genus Sus. Technical Bulletin Number 3. Pages 1-96. Department of Prehistory, Research School of Pacific Studies, Australian National University, Canberra, Australia.

Hanski, I. 1991. The functional response of predators: wor- 
ries about scale. Trends in Evolution and Ecology 6:141142.

Harper, J. L. 1977. Population biology of plants. Academic Press, London, UK.

Harper, J. L., and J. White. 1974. The demography of plants. Annual Review of Ecology and Systematics 5:419-463.

Holt, R. D. 1984. Spatial heterogeneity, indirect interactions, and the coexistence of prey species. American Naturalist 124:377-406.

Holt, R. D., and J. H. Lawton. 1994. The ecological consequences of shared natural enemies. Annual Review of Ecology and Systematics 25:495-520.

Howe, H. F., E. W. Schupp, and L. C. Westley. 1985. Early consequences of seed dispersal for a neotropical tree ( $\mathrm{Vi}$ rola surinamensis). Ecology 66:781-791.

Hubbell, S. P. 1980. Seed predation and the coexistence of tree species in tropical forests. Oikos 35:214-229.

Ims, R. A. 1990. On the adaptive value of reproductive synchrony as a predator-swamping strategy. American Naturalist 136:485-498.

Indonesian Forestry Department. 1991. Statistik Kehutanan Indonesia. Sekretariat Jenderal Departemen Kehutanan, Biro Perencanaan, Jakarta, Indonesia.

Janzen, D. H. 1969. Seed-eaters versus seed size, number, dispersal and toxicity. Evolution 23:1-27.

Janzen, D. H. 1970. Herbivores and the number of tree species in tropical forests. American Naturalist 104:501-528.

Janzen, D. H. 1971. Seed predation by animals. Annual Review of Ecology and Systematics 2:465-492.

Janzen, D. H. 1974. Tropical blackwater rivers, animals and mast fruiting by the Dipterocarpaceae. Biotropica 4:69103.

Janzen, D. H. 1976. Why bamboos wait so long to flower. Annual Review of Ecology and Systematics 7:347-391.

Janzen, D. H. 1978. Seedling patterns of tropical trees. Pages 83-128 in P. B. Tomlinson and M. H. Zimmermann, editors Tropical trees as living systems. Cambridge University Press, Cambridge, UK.

Janzen, D. H., and C. Vázquez-Yanes. 1991. Aspects of tropical seed ecology of relevance to management of tropical forested wildlands. Pages 137-157 in A. Gómez-Pompa, T. C. Whitmore, and M. Hadley, editors. Rain forest regeneration and management. Volume 6. Man in the Biosphere Series. UNESCO-MAB, Paris, France.

Jensen, T. S. 1982. Seed production and outbreaks of noncyclic rodent populations in deciduous forests. Oecologia 54:184-192.

Jensen, T. S. 1985. Seed-seed predator interactions of European beech, Fagus silvatica, and forest rodents, Cleth rionomys glareolus and Apodemus flavicollis. Oikos 44 149-156.

Johns, A. D. 1988. Effects of "selective" timber extraction on rain forest structure and composition and some consequences for frugivores and folivores. Biotropica 20:31-37.

Johns, A. D. 1992. Species conservation in managed tropical forests. Pages 15-54 in T. C. Whitmore and J. A. Sayer, editors. Tropical deforestation and species extinction. IUCN Forest Conservation Programme. Chapman and Hall, New York, New York, USA.

Johnsgard, P. A. 1988. The quail, partridges and francolins of the World. Oxford University Press, Oxford, UK.

Karban, R. 1982. Increased reproductive success at high densities and predator satiation for periodical cicadas. Ecology 63:321-328

Kelly, D. 1994. The evolutionary ecology of mast seeding. Trends in Ecology and Evolution 9:465-470.

Kilte, R. A. 1988. Gestation as a constraint on the evolution of seasonal breeding in mammals. Pages 257-289 in M. S. Boyce, editor. Evolution of life histories of mammals: the- ory and pattern. Yale University Press. New Haven, Connecticut, USA.

Koenig, W. D., and J. Knops. 1995. Why do oaks produce boom-and-bust seed crops? California Agriculture 49:712 .

Koenig, W. D., R. L. Mumme, W. J. Carmen, and M. T. Stanback. 1994. Acorn production by oaks in central coastal California: variation within and among years. Ecology 75:99-109.

LaFrankie, J. V., and H. T. Chan. 1991. Confirmation of sequential flowering in Shorea (Dipterocarpaceae). Biotropica 23:200-203.

Lalonde, R. G., and B. D. Roitberg. 1992. On the evolution of masting behavior in trees: predation or weather? American Naturalist 139:1293-1304.

Leighton, M. 1993. Modeling diet selectivity by Bornean orangutans: evidence for integration of multiple criteria in fruit selection. International Journal of Primatology 14: 257-313.

Leighton, M., and D. R. Leighton. 1983. Vertebrate response to fruiting seasonality within a Bornean rain forest. Pages 181-196 in S. L. Sutton, T. C. Whitmore, and A. C. Chadwick, editors. Tropical rain forest: ecology and management. Blackwell Scientific, Oxford, UK.

Leighton, M., and N. Wirawan. 1986. Catastrophic drought and fire in Borneo tropical forest associated with the 198283 El Niño Southern-Oscillation event. Pages 75-102 in G. T. Prance, editor. Tropical forests and the world atmosphere. American Association for the Advancement of Science, Washington, D.C., USA.

Ligon, J. D. 1974. Green cones of the piñon pine stimulate late summer breeding in the Piñon Jay. Nature 250:80-82.

Ligon, J. D. 1978. Reproductive interdependence of Piñon Jays and piñon pines. Ecological Monographs 48:111-126.

Lima, S. L., and P. A. Zollner. 1996. Towards a behavioral ecology of ecological landscapes. Trends in Ecology and Evolution 11:131-135.

Louda, S. M. 1982a. Limitations of the recruitment of the shrub, Haplopappus squarrosus (Asteraceae) by flowerand seed-feeding insects. Journal of Ecology 70:43-53.

Louda, S. M. 1982b. Distribution ecology: variation in plant recruitment over a gradient in relation to insect seed predation. Ecological Monographs 52:25-41.

Lyal, C. H. C., and L. M. Curran. 2000. Seed-feeding beetles of the weevil tribe Mecysolobini (Insecta: Coleoptera, Curculionidae) developing in the seeds of trees in the Dipterocarpaceae. Journal of Natural History, in press.

McClure, H. E. 1966. Flowering, fruiting and animals in the canopy of a tropical rain forest. Malaysian Forester 29: 182-203.

McShea, W. J., and G. Schwede. 1993. Variable acorn crops: responses of white-tailed deer and other mast consumers. Journal of Mammalogy 74:999-1006.

Medway, Lord. 1972. Phenology of tropical rain forest in Malaya. Biological Journal of the Linnean Society 4:117146.

Mellen, I. M. 1952. The natural history of the pig. Exposition Press, New York, USA.

Mitchell, M. H. 1935. The Passenger Pigeon in Ontario. University of Toronto Press, Toronto, Ontario, Canada.

Newton, I. 1972. Finches. Collins, London, UK.

Nilsson, S. G. 1985. Ecological and evolutionary interactions between reproduction of beech Fagus sylvatica and seed eating animals. Oikos 44:157-164.

Nilsson, S. G., and U. Wästljung. 1987. Seed predation and cross-pollination in mast-seeding beech (Fagus sylvatica) patches. Ecology 68:260-265.

Norton, D. A., and D. Kelly. 1988. Mast seeding over 33 years by Dacrydium cupressinum Lamb. (rimu) (Podocar- 
paceae) in New Zealand: the importance of economies of scale. Functional Ecology 2:221-227.

O'Dowd, D. J., and A. M. Gill. 1984. Predator satiation and site alteration following fire: mass reproduction of alpine ash (Eucalyptus delegatensis) in southeastern Australia. Ecology 65:1052-1066.

Payne, J., C. Francis, and K. Phillips. 1985. A field guide to the mammals of Borneo. Sabah Society, Kota Kinabalu and World Wildlife Fund, Kuala Lumpur, Malaysia.

Perrins, C. M. 1966. The effect of beech crops on Great Tit populations and movements. British Birds 59:419-432.

Pfeffer, P. 1959. Biologie et migrations du sanglier de Borneo (Sus barbatus Müller 1869). Mammalia 23:277-303.

Pfeffer, P., and J. Caldecott. 1986. The bearded pig (Sus barbatus) in East Kalimantan and Sarawak. Journal of the Malaysian Branch of the Royal Asiatic Society 59:81-100.

Rasmusson, E. M. 1985. El Niño and variation in climate. American Scientist 73:168-177.

Salafsky, N. 1988. The foraging patterns and socioecology of the kelasi (Presbytis rubicunda). Undergraduate thesis, Harvard University, Cambridge, Massachusetts, USA.

Salafsky, N. 1994. Drought in the rain forest: Effects of the 1991 El Niño-Southern Oscillation event on a rural economy in West Kalimantan, Indonesia. Climate Change 27: 373-396.

Salisbury, E. J. 1942. The reproductive capacity of plants. Bell, London, UK.

Schorger, A. W. 1955. The Passenger Pigeon: its natural history and extinction. University of Wisconsin Press, Madison, Wisconsin, USA.

Schorger, A. W. 1966. The Wild Turkey: its history and domestication. University of Oklahoma Press, Norman, Oklahoma, USA.

Schupp, E. 1987. Studies on seed predation of Faramea occidentalis, an abundant tropical tree. Dissertation. University of Iowa, Iowa City, Iowa, USA.

Schupp, E. 1988. Seed and early seedling predation in the forest understory and in treefall gaps. Oikos 51:71-78.

Schupp, E. 1990. Annual variation in seedfall, post-dispersal predation, and recruitment of a neotropical tree. Ecology 71:504-515.

Shelford, R. W. C. 1917. Naturalist in Borneo. T. F. Unwin, London, UK.

Silvertown, J. 1980. The evolutionary ecology of mast seeding in trees. Biological Journal of the Linnean Society $\mathbf{1 4}$ $235-250$.

Silvertown, J. 1982. Introduction to plant population ecology. Longman, London, UK.

Smith, C. C., J. L. Hamrick, and C. L. Kramer. 1990. The advantage of mast years for wind pollination. American Naturalist 136:154-166.

Smythies, B. E. 1960. Birds of Borneo. Third edition. The Sabah Society with The Malayan Nature Society. Kota Kinabalu, Sabah, Malaysia.

Sork, V. L. 1987. Effects of predation and light on seedling establishment in Gustavia superba. Ecology 68:1341-1350.

Sork, V. L. 1993. Evolutionary ecology of mast-seeding in temperate and tropical oaks (Quercus spp.). Vegetatio 107/ 108:133-147.

Sork, V. L., and D. H. Boucher. 1977. Dispersal of sweet pignut hickory in a year of low fruit production and the influence of predation by a curculionid beetle. Oecologia 28:289-299.

Sork, V. L., J. Bramble, and O. Sexton. 1993. Ecology of mast-fruiting in three species of North American oaks. Ecology 74:528-541.

Spitz, F., and G. Janeau. 1995. Daily selection of habitat in wild boar (Sus scrofa). Journal of Zoology 237:423-434.
Stoddard, H. L. 1931. The Bobwhite Quail: its habits, preservation and increase. Charles Scribner's, New York, New York, USA.

Svärdson, G. 1957. The "invasion" type of bird migration. British Birds 50:314-343.

Sweeney, B. W., and R. L. Vannote. 1982. Population synchrony in mayflies: a predator satiation hypothesis. Evolution 36:810-821.

Tantra, I. G. M. 1977. The establishment of tengkawang (Shorea spp.) plantations in Indonesia. Pages 232-241 in Biotrop Special Publication Number 4. Proceedings of the Symposium on Management of Forest Production in Southeast Asia. April, 1977, Bangkok, SEAMEO Regional Center for Tropical Biology. Bogor, Indonesia.

Tapper, P. 1996. Long-term patterns of mast fruiting in Fraxinus excelsior. Ecology 77:2567-2572.

Toy, R. J., A. J. Marshall, and T. Y. Pong. 1992. Fruiting phenology and the survival of insect fruit predators: a case study from the South-east Asian Dipterocarpaceae. Philosophical Transactions of the Royal Society of London, Series B, 335:417-423.

Trenberth, K. E. 1997. The definition of El Niño. Bulletin of the American Meterological Society 78:2771-2777.

Trenberth, K. E., and T. J. Hoar. 1996. The 1990-1995 El Niño-Southern Oscillation event: longest on record. Geophysical Research Letters 23:57-60.

Waller, D. M. 1979. Models of mast-fruiting in trees. Journal of Theoretical Biology 80:223-232.

Waller, D. M. 1993. How does mast-fruiting get started? Trends in Ecology and Evolution 8:122-123.

Ward, P., and A. Zahavi. 1972. The importance of certain assemblages of birds as "information centres" for foodfinding. Ibis 115:517-534.

Wheelwright, N. T. 1985. Competition for dispersers, and the timing of flowering and fruiting in a guild of tropical trees. Oikos 44:465-477.

Wheelwright, N. T. 1986. A seven-year study of individual variation in fruit production in tropical bird-dispersed tree species in the family Lauraceae. Pages 19-35 in A. Estrada and T. H. Fleming, editors. Frugivores and seed dispersal. Dr. Junk, The Hague, The Netherlands.

Whitmore, T. C. 1984. Tropical rain forests of the Far East. Second edition. Oxford Science Publications, Clarendon Press, Oxford, UK.

Wiens, J. A. 1989. Spatial scaling in ecology. Functional Ecology 3:385-397.

Williams, K. S., K. G. Smith, and F. M. Stephen. 1993. Emergence of 13-yr periodical cicadas (Cicadidae: Magicicada): Phenology, mortality, and predator satiation. Ecology 74: 1143-1152.

Williams, L. E., Jr. 1981. The book of the Wild Turkey. Winchester Press, Tulsa, Oklahoma, USA.

Wolff, J. O. 1996. Population fluctuations of mast-eating rodents are correlated with production of acorns. Journal of Mammalogy 77:850-856.

Wood, G. H. S. 1956. The dipterocarp flowering season in North Borneo, 1955. Malayan Forester 19:193-201.

Wright, S. J. 1990. Cumulative satiation of a seed predator over the fruiting season of its host. Oikos 58:272-276.

Wright, S. J., C. Carrasco, O. Calderón, and S. Paton. 1999. The El Niño-Southern Oscillation, variable fruit production, and famine in a tropical forest. Ecology 80:16321647.

Yap, S. K., and H. T. Chan. 1990. Phenological behaviour of some Shorea species in Peninsular Malaysia. Pages 2135 in K. S. Bawa and M. Hadley, editors. Reproductive ecology of tropical forest plants. Man in the Biosphere Series, Volume 7. UNESCO-MAB, Paris, France. 
APPENDIX A

A list of the Dipterocarpaceae in the Gunung Palung National Park, West Kalimantan, Indonesia, is available in ESA's Electronic Data Archive: Ecological Archives, M070-002.

\section{APPENDIX B}

Vertebrate seed predators in Gunung Palung National Park, West Kalimantan. Nomenclature follows Payne et al. (1985) for mammals and Smythies (1960) for birds.

\begin{tabular}{|c|c|c|c|c|c|c|c|}
\hline & Species & Activity $\dagger$ & Strata $\$$ & $\begin{array}{l}\text { Body } \\
\text { size§ }\end{array}$ & $\begin{array}{l}\text { Social } \\
\text { system } \|\end{array}$ & RangeףI & $\begin{array}{l}\text { Seed-eating } \\
\text { mode\# }\end{array}$ \\
\hline \multicolumn{8}{|c|}{ A) Order Primata } \\
\hline \multicolumn{8}{|c|}{ Family Cercopithecidae } \\
\hline & $\begin{array}{l}\text { Nasalis larvatus } \\
\text { Presbytis rubicunda } \\
\text { Presbytis cristata } \\
\text { Macaca fasicularis } \\
\text { Macaca nemenstrina }\end{array}$ & $\begin{array}{l}\mathrm{D} \\
\mathrm{D} \\
\mathrm{D} \\
\mathrm{D} \\
\mathrm{D}\end{array}$ & $\begin{array}{l}\text { A } \\
\text { A } \\
\text { A } \\
\text { A } \\
\text { A }\end{array}$ & $\begin{array}{l}10 ; 20 \\
6 ; 7 \\
5 ; 6 \\
3.5 ; 6 \\
5 ; 8\end{array}$ & $\begin{array}{l}\text { H } \\
\text { RDP } \\
\text { RDP? } \\
\text { MM } \\
\text { MM }\end{array}$ & $\begin{array}{l}\mathrm{R} \\
\mathrm{R} \\
\mathrm{R} \\
\mathrm{R} \\
\mathrm{N}\end{array}$ & $\begin{array}{l}\mathrm{P} \\
\mathrm{P} \\
\mathrm{P} \\
\mathrm{D} / \mathrm{P} \\
\mathrm{D} / \mathrm{P}\end{array}$ \\
\hline \multicolumn{8}{|c|}{ Family Hylobatidae } \\
\hline & Hylobates agilis & $\mathrm{D}$ & A & 5.5 & MO & $\mathrm{R}$ & $\mathrm{D} \sim \mathrm{P}$ \\
\hline \multicolumn{8}{|c|}{ Family Pongidae } \\
\hline & Pongo pygmaeus female & $\mathrm{D}$ & A & 35 & SOL & $\mathrm{R}$ & $\mathrm{D} / \mathrm{P}$ \\
\hline & Pongo pygmaeus male & $\mathrm{D}$ & $\mathrm{T} / \mathrm{A}$ & 100 & SOL & $\mathrm{N}$ & $\mathrm{P} / \mathrm{D}$ \\
\hline \multirow[t]{3}{*}{ B) } & Order Artiodactyla & & & & & & \\
\hline & Family Suidae & & & & & & \\
\hline & Sus barbatus & $\mathrm{C}$ & $\mathrm{T}$ & $80-150$ & SOL & $\mathrm{N}$ & $\mathrm{P}$ \\
\hline \multirow[t]{7}{*}{ C) } & \multicolumn{7}{|l|}{ Order Rodentia } \\
\hline & \multicolumn{7}{|l|}{ Family Sciuridae } \\
\hline & $\begin{array}{l}\text { Ratufa affinis } \\
\text { Callosciurus prevostii } \\
\text { Callosciurus notatus } \\
\text { Rheithosciurus macrotis } \\
\text { Lariscus insignius } \\
\text { Sundasciurus hippurus } \\
\text { Sundasciurus lowii } \\
\text { Sundasciurus tenuis } \\
\text { Aeromys tephromelas } \\
\text { Aeromys thomasi } \\
\text { Aeromys petaurista }\end{array}$ & $\begin{array}{l}D \\
D \\
D \\
D \\
D \\
D \\
D \\
D \\
D \\
N \\
N \\
N\end{array}$ & $\begin{array}{l}\text { A } \\
\text { A } \\
\text { A } \\
\text { A/T } \\
\text { T } \\
\text { A/T } \\
\text { A/T } \\
\text { A/T } \\
\text { A } \\
\text { A } \\
\text { A }\end{array}$ & $\begin{array}{l}1.5 \\
0.5 \\
0.3 \\
1.3 \\
0.4 \\
0.1 \\
\\
0.9 \\
1.5 \\
3\end{array}$ & $\begin{array}{l}\text { SOL } \\
\text { SOL } \\
\text { SOL } \\
\text { SOL } \\
\text { SOL } \\
\text { SOL } \\
\text { SOL } \\
\text { SOL }\end{array}$ & $\begin{array}{l}\mathrm{R} \\
\mathrm{R} \\
\mathrm{R} \\
\mathrm{R} / \mathrm{N} ? \\
\mathrm{R} \\
\mathrm{R} \\
\mathrm{R} \\
\mathrm{R}\end{array}$ & $\begin{array}{l}\mathrm{P} \\
\mathrm{P} \\
\mathrm{P} \\
\mathrm{P} \\
\mathrm{P} / \mathrm{D} \\
\mathrm{S} / \mathrm{P} \\
\mathrm{S} / \mathrm{P} \\
\mathrm{S} / \mathrm{P}\end{array}$ \\
\hline & \multicolumn{7}{|l|}{ Family Muridae } \\
\hline & $\begin{array}{l}\text { Sundamys muelleri } \\
\text { Maxomys rajah } \\
\text { Maxomys surifer } \\
\text { Maxomys whiteheadi } \\
\text { Leopoldamys sabanus }\end{array}$ & $\begin{array}{l}\mathrm{N} \\
\mathrm{N} \\
\mathrm{N} \\
\mathrm{N} \\
\mathrm{N}\end{array}$ & $\begin{array}{l}\mathrm{T} \\
\mathrm{T} \\
\mathrm{T} \\
\mathrm{T} \\
\mathrm{A} / \mathrm{T}\end{array}$ & $\begin{array}{l}0.3 \\
0.16 \\
0.13 \\
0.04 \\
0.36\end{array}$ & $\begin{array}{l}\text { SOL } \\
\text { SOL } \\
\text { SOL } \\
\text { SOL } \\
\text { SOL }\end{array}$ & $\begin{array}{l}\mathrm{R} \\
\mathrm{R} \\
\mathrm{R} \\
\mathrm{R} \\
\mathrm{R}\end{array}$ & $\begin{array}{l}\mathrm{P} / \mathrm{L} \\
\mathrm{P} / \mathrm{L} \\
\mathrm{P} / \mathrm{L} \\
\mathrm{P} / \mathrm{L} \\
\mathrm{P} / \mathrm{L}\end{array}$ \\
\hline & \multicolumn{7}{|l|}{ Family Hystricidae } \\
\hline & $\begin{array}{l}\text { Trichys fasciculata } \\
\text { Hystrix brachyura }\end{array}$ & $\begin{array}{l}\mathrm{N} \\
\mathrm{N}\end{array}$ & $\begin{array}{l}\mathrm{T} \\
\mathrm{T}\end{array}$ & $\begin{array}{l}2 \\
3\end{array}$ & $\begin{array}{l}\text { SOL } \\
\text { SOL }\end{array}$ & $\begin{array}{l}\mathrm{R} ? \\
\mathrm{R} ?\end{array}$ & $\begin{array}{l}\mathrm{S} / \mathrm{P} \\
\mathrm{S} / \mathrm{P}\end{array}$ \\
\hline \multirow[t]{2}{*}{ D) } & $\begin{array}{l}\text { Order Psittaciformes } \\
\text { Family Psittacidae }\end{array}$ & & & & & & \\
\hline & $\begin{array}{l}\text { Psittacula longicauda } \\
\text { Psittinus cyanurus } \\
\text { Loriculus galgulus }\end{array}$ & $\begin{array}{l}\mathrm{D} \\
\mathrm{D} \\
\mathrm{D}\end{array}$ & $\begin{array}{l}\text { A } \\
\text { A } \\
\text { A }\end{array}$ & $\begin{array}{l}42 \mathrm{~cm} ; 0.1 \mathrm{~kg} \\
12 \mathrm{~cm} \\
13\end{array}$ & $\begin{array}{l}\text { COL:PR } \\
\text { COL:PR } \\
\text { PR }\end{array}$ & $\begin{array}{l}\mathrm{N} \\
\mathrm{N} \\
\mathrm{N}\end{array}$ & $\begin{array}{l}\mathrm{P} \\
\mathrm{P} \\
\mathrm{P} ? / \mathrm{D} ?\end{array}$ \\
\hline \multirow[t]{3}{*}{ E) } & Order Columbiformes & & & & & & \\
\hline & Family Columbidae & & & & & & \\
\hline & Chalcophaps indica & $\mathrm{D}$ & $\mathrm{T}$ & 25 & PR & $\mathrm{N}$ & $\mathrm{P}$ \\
\hline
\end{tabular}


APPENDIX B. Continued.

\begin{tabular}{|c|c|c|c|c|c|c|}
\hline Species & Activity $\dagger$ & Strata & $\begin{array}{l}\text { Body } \\
\text { size§ }\end{array}$ & $\begin{array}{c}\text { Social } \\
\text { system } \|\end{array}$ & RangedI & $\begin{array}{l}\text { Seed-eating } \\
\text { mode\# }\end{array}$ \\
\hline \multicolumn{7}{|l|}{ F) Order Galliformes } \\
\hline \multicolumn{7}{|l|}{ Family Phasianidae } \\
\hline Rollulus rouloul & $\mathrm{D}$ & $\mathrm{T}$ & 25 & $\mathrm{H}$ & $\mathrm{N}$ & $\mathrm{P}$ \\
\hline Haematortyx sanguiniceps & $\mathrm{D}$ & $\mathrm{T}$ & 25 & PR & $\mathrm{N}$ & $\mathrm{P}$ \\
\hline Melanoperdix nigra & $\mathrm{D}$ & $\mathrm{T}$ & 25 & PR & $\mathrm{N}$ & $\mathrm{P}$ \\
\hline Lophura erythrophthalma & $\mathrm{D}$ & $\mathrm{T}$ & 51 & PR? & $\mathrm{N}$ & $\mathrm{P}$ \\
\hline Lophura ignita & $\mathrm{D}$ & $\mathrm{T}$ & 56 & $\mathrm{PR}$ & $\mathrm{N}$ & $\mathrm{P}$ \\
\hline Lophura bulweri & $\mathrm{D}$ & $\mathrm{T}$ & 51,78 & PR & $\mathrm{N}$ & $\mathrm{P}$ \\
\hline Argusianus argus & $\mathrm{C}$ & $\mathrm{T}$ & 61,168 & LEK & $\mathrm{R}$ & $\mathrm{D}$ ? \\
\hline
\end{tabular}

Notes: Only large lowland forest Muridae and flying squirrels sighted in the area are included, and body mass data are based on Gunung Palung trapping data. Where cells are blank, the information is unknown.

$\dagger$ Codes: D, diurnal; C, crepuscular; N, nocturnal.

$\$$ Codes: A, arboreal; T, terrestrial.

$\S$ Data for mammals are body mass (in kilograms) for females first, then males (Payne et al. 1985). Data for birds are body lengths (in cm; Smythies 1960). Body mass is given for Psittacula longicauda and lengths of females, then males are given for Lophura bulweri and Argusianus argus.

I Codes: H, harem; RDP, resource defense polygyny; MM, multimale and multifemale; MO, monogamous; SOL, solitary; COL, colonial; PR, pair; LEK, lek.

If Codes: R, resident year-round; N, nomadic or migrant, with large ranges or considerable seasonal fluctuation in local population density.

\# Codes: P, predator; D, disperser; S, scatterhoarder; L, larderhoarder. 